Check for updates

Cite this: RSC Adv., 2017, 7, 47335

Received 28th June 2017

Accepted 30th September 2017

DOI: $10.1039 / \mathrm{c} 7 \mathrm{ra07176k}$

rsc.li/rsc-advances

\section{Synthesis and assessment of new cationic gemini surfactants as inhibitors for carbon steel corrosion in oilfield water $\dagger$}

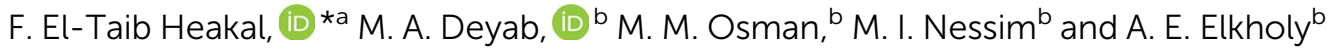

Three gemini surfactants were synthesized having the same length of terminal chain but differing in the spacer chain length and they were evaluated as corrosion inhibitors for carbon steel in oilfield water using weight loss, EIS, potentiodynamic polarization and open-circuit potential measurements. These measurements revealed that the synthesized materials have served as effective mixed-type corrosion inhibitors. Their adsorption on a carbon steel surface was well described by means of the Langmuir adsorption isotherm. The activation parameters for the dissolution of carbon steel in solutions of oilfield water in the absence and presence of these inhibitors were calculated. The effect of immersion time on the stability and durability of protective films adsorbed on a carbon steel surface was studied using weight loss method. Ex situ inspection, i.e. post-exposure analysis, for the treated carbon steel surface has been performed using SEM, EDX and FT-IR tools.
\end{abstract}

\section{Introduction}

Carbon steel (C-steel) is the main engineering material used in constructing pipelines for transferring water, chemicals and petroleum products in addition to vessels used in oil and gas production systems. This broad usage of carbon steel is due to its excellent mechanical properties and cheapness. ${ }^{1,2}$ Unfortunately, carbon steel-based materials are vulnerable to corrosion by their neighboring environment. Among the corrosive media doing violence to C-steel is oilfield water which naturally exists in gas and oil reservoirs. It contains huge amounts of dissolved salts (e.g. chloride and sulfate ions) and dissolved corrosive gases (e.g. $\mathrm{CO}_{2}$ and $\mathrm{H}_{2} \mathrm{~S}$ ) as well. ${ }^{3}$ In petroleum oilfields, the disposal of oilfield water separated from crude oil represents a nuisance for workers in the petroleum industry because it is highly saline and polluted by oil. So, this water is mixed with fresh water and re-injected in the oil wells so as to stimulate the crude oil stuck to rocks in the oil reservoir to be recovered with the advantage of increasing the oil productivity on one hand and the disposal of oilfield water on the other hand in a process called hydraulic fracturing. Before injection, some chemicals are added to this fluid such as scale and corrosion inhibitors to prevent scale deposition inside oil pipelines and also to prevent their corrosion. ${ }^{4}$

${ }^{a}$ Chemistry Department, Faculty of Science, Cairo University, 12613 Giza, Egypt. E-mail: fakihaheakal@yahoo.com; feltaibheakal@gmail.com; Fax: +20 35738425; Tel: +201002449048

${ }^{b}$ Department of Analysis and Evaluation, Egyptian Petroleum Research Institute, 11727 Cairo, Egypt

$\dagger$ Electronic supplementary information (ESI) available. See DOI: 10.1039/c7ra07176k
Among the methods followed for protecting metals against their corrosion is using corrosion inhibitors. It is the most suitable procedure because of its high efficiency, economic advantages, and wide applicability in various fields. ${ }^{5}$ A corrosion inhibitor is any material that can reduce the corrosion rate of a metal ${ }^{6}$ via displacing water molecules from the vicinity of the metallic surface then its molecules can interact with the anodic and/or cathodic sites by adsorption. ${ }^{7}$ These materials can be classified according to their chemical nature into three genres: (i) inorganic inhibitors, (ii) organic inhibitors, and (iii) mixed-compound inhibitors. ${ }^{8}$ Nevertheless, most commonly used inhibitors are organic compounds especially those containing hetero atoms $(\mathrm{O}, \mathrm{N} \text { and/or } \mathrm{S})^{9}$ and/or those containing multiple bonds or aromatic rings $\left(\pi\right.$-systems). ${ }^{10}$ Inhibition process can be performed by electrons transfer between the inhibitor and the metal surface (vacant d-orbitals) forming coordinate covalent bonds between them. ${ }^{11}$ Furthermore, adsorption can be due to electrostatic interaction between the metal surface and inhibitor molecules. ${ }^{12}$ As a result, inhibitor adsorption relies on the surface charge of the metal, i.e., the adsorption of cations is favored if the net charge is negative while adsorption of anions is favored when the case is reversed. ${ }^{11}$

Surfactants, or surface active agents, are a general class of organic chemical compounds of amphiphilic molecules, each of them contains a hydrophobic (non-polar) tail and a hydrophilic (polar) head. ${ }^{13}$ Usually, the hydrophilic head (either polar or ionic group) of surfactant molecule attaches to the metal surface and its tail or hydrophobic moiety extends away from the interface towards the solution bulk forming an array of hydrophobic tails which leads to a change in the 


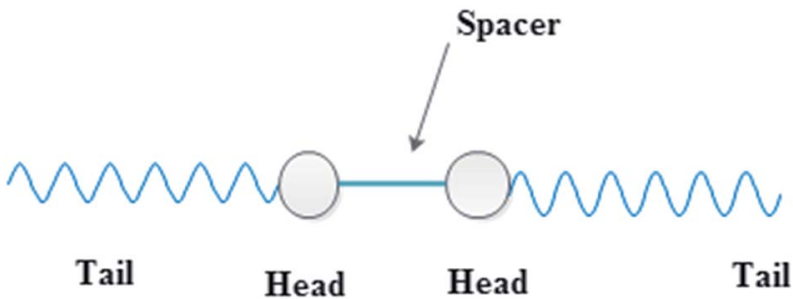

Fig. 1 Shape of gemini surfactant molecule.

electrochemical behavior of metal (increasing the corrosion resistance). ${ }^{14}$ Gemini surfactants are a class of surfactants in which the molecule is composed of two identical molecules of ordinary surfactant linked together via a linkage called spacer (Fig. 1). ${ }^{15}$ This spacer may be hydrophilic or hydrophobic, short or long and rigid or flexible. ${ }^{16}$ The current study aims to investigate the corrosion inhibition efficiency of some developed cationic gemini surfactants for C-steel in oilfield water. These surfactants were prepared in the series of $\alpha, \omega$-alkanediyl bis(3dodecylimidazolium-1-yl)dibromide with the same length of terminal chains but differing in the length of spacer chain $(2,6$ and 10 methylene groups).

\section{Materials and experimental methods}

\subsection{Materials}

Carbon steel samples used in all experiments has the following elemental composition (in wt\%): $0.200 \mathrm{C}, 0.350 \mathrm{Mn}, 0.024 \mathrm{P}$, $0.003 \mathrm{Si}$ and balance Fe. C-steel electrode and weight loss coupons were polished before each experiment with several emery sheets ranging from 400 to 2500 grades, washed with distilled water and dried using a filter paper.

The test solution used in this study was oilfield water free from oils and greases. It was collected from several Egyptian oilfields. The physical properties and chemical composition of oilfield water are shown in Tables 1 and 2, respectively. The components of this medium are known to be highly corrosive to the oil extraction structures. ${ }^{17,18}$

Anions and cations of oilfield water were determined according to ASTM D-4327 and 6919, respectively using ion chromatography. The instrument used was Dionex IC model ICS 1100 equipped with high capacity columns (AS9 and CS12) for anion and cations, respectively. Heavy metals present in oilfield water were determined using Flame Atomic Absorption Spectrophotometer model Zenit 700p according to ASTM D4691. Physical properties of oilfield water including density, specific gravity, $\mathrm{pH}$, etc., were measured according to the following standard procedures:

- TDS was determined according to ASTM D-1888.

- Conductivity and resistivity was determined on site using digital conductivity meter WTW 330I according to ASTM D1125.

- Density and specific gravity was determined according to ASTM D-1429.
Table 1 Physical properties of oilfield water

\begin{tabular}{|c|c|}
\hline Physical property & Value \\
\hline Total dissolved solids & $111.9255 \mathrm{~g} \mathrm{l}^{-1}$ \\
\hline Conductivity & $\begin{array}{l}14.61 \mathrm{mohs} \mathrm{cm}^{-1} \text { @ } 20.1 \\
{ }^{\circ} \mathrm{C}\end{array}$ \\
\hline Resistivity & $0.0685 \mathrm{ohm} \mathrm{m} @ 20.1^{\circ} \mathrm{C}$ \\
\hline Salinity & $109.5072 \mathrm{~g} \mathrm{l}^{-1}$ \\
\hline $\mathrm{pH}$ & 6.85 @ $25^{\circ} \mathrm{C}$ \\
\hline Density & $1.0842 \mathrm{~g} \mathrm{ml}^{-1}$ @ $15.56^{\circ} \mathrm{C}$ \\
\hline Specific gravity & 1.0853 \\
\hline Hardness & $25.0657 \mathrm{~g} \mathrm{l}^{-1}$ \\
\hline
\end{tabular}

Table 2 Chemical composition of oilfield water

\begin{tabular}{llll}
\hline Constituents & $\begin{array}{l}\text { Concentration } \\
\left(\mathrm{mg} \mathrm{l}^{-1}\right)\end{array}$ & Constituents & $\begin{array}{l}\text { Concentration } \\
\left(\mathrm{mg} \mathrm{l}^{-1}\right)\end{array}$ \\
\hline Lithium & 0.01 & Fluoride & 0.00 \\
Sodium & 30543.00 & Chloride & 66368.00 \\
Potassium & 3402.13 & Bromide & 209.45 \\
Magnesium & 1197.24 & Nitrate & Nil \\
Calcium & 8063.85 & Hydroxide & Nil \\
Iron & 38.69 & Carbonate & Nil \\
Copper & 0.15 & Bicarbonate & 244.00 \\
Strontium & Nil & Sulfate & 1859.00 \\
Barium & Nil & & \\
& & &
\end{tabular}

- $\mathrm{pH}$ value was determined according to ASTM D-1293 using digital pH meter model Mettler Toledo-Seven Go.

- Alkaline species $\left(\mathrm{CO}_{3}{ }^{2-}, \mathrm{OH}^{-}\right.$, and $\left.\mathrm{HCO}_{3}{ }^{-}\right)$were measured according to ASTM D-3875 calculations was done using Alkalinity calculator ver. 2.10 (USGS).

The corrosion inhibitors used in this study are some cationic gemini surfactants differing in the length of spacer chain (2, 6 and 10 methylene groups). For simplicity, they are abbreviated according to their spacer length as GS2, GS6 and GS10, respectively. The chemicals from which these gemini surfactants are prepared have been purchased from Alfa Aesar Co. These chemicals are namely, $1 H$-imidazole (99\%), 1-bromododecane (98\%), 1,2-dibromoethane (99\%), 1,6-dibromohexane (97\%), 1,10-dibromo decane (97\%), acetonitrile (HPLC grade) and $\mathrm{KOH}$ (pellets).

\subsection{Synthesis of gemini surfactants}

The three imidazolium-based gemini surfactants are prepared through two steps as follows:

2.2.1. Synthesis of 1-dodecyl- $1 \mathrm{H}$-imidazole. 1-Dodecy- $1 H^{-}$ imidazole represents the monomeric form (the intermediate compound) of the three gemini surfactants under study. It was prepared by mixing 0.1 mol dodecyl bromide $(2.49 \mathrm{~g})$ with $0.1 \mathrm{~mol}$ imidazole $(6.8 \mathrm{~g})$ and $5.6 \mathrm{~g} \mathrm{KOH}$ in $50 \mathrm{ml}$ acetonitrile as a solvent (Scheme 1). This mixture was continuously stirred at room temperature for about three hours. The product (the monomer dissolved in acetonitrile) was filtered off from the precipitate $(\mathrm{KBr})$. The final product was recrystallized from acetonitrile by evaporation under vacuum. 


$$
\begin{aligned}
& \left\langle\stackrel{\mathrm{N}}{\|}+\mathrm{C}_{12} \mathrm{H}_{25}-\mathrm{Br} \frac{\mathrm{CH}_{3} \mathrm{CN}}{\mathrm{KOH}}\right. \\
& \mathrm{H} \\
& 1 H \text {-imidazole dodecyl bromide }
\end{aligned}
$$

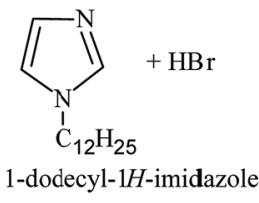

Scheme 1 Synthetic route for 1-dodecyl-1H-imidazole.

2.2.2. Synthesis of gemini surfactants. The desired gemini surfactants (GS2, GS6 and GS10) were synthesized by a coupling reaction between 1-dodecyl- $1 H$-imidazole $(0.2 \mathrm{~mol})$ with 1,2dibromoethane, 1,6-dibromohexane and 1,10-dibromodecane (0.1 mol), respectively in $50 \mathrm{ml}$ acetonitrile (Scheme 2). The reaction mixture was refluxed for $12 \mathrm{~h}$ at $80^{\circ} \mathrm{C}$. Produced gemini surfactants were recrystallized from acetonitrile by evaporation under vacuum.

\subsection{Characterization of the synthesized gemini surfactants}

The synthesized gemini surfactants were characterized using elemental analysis, mass spectrometry, Fourier transform infrared (FT-IR) spectroscopy and $\mathrm{H}^{1}$-NMR spectroscopy. Mass spectrometric analysis was performed using Thermo Scientific ISQ QD GC-MS system. FT-IR spectroscopic analysis was performed using $\mathrm{KBr}$ pellets via Perkin Elmer, model: Spectrum One FT-IR spectrometer. $\mathrm{H}^{1}$-NMR spectroscopy was carried out in $\mathrm{CDCl}_{3}$ using Varian Gemini-200 $\mathrm{MHz}$ system. Thermogravimetric analysis (TGA) was carried out for the synthesized surfactants to determine their thermal stability using simultaneous TGA-DSC, model: SDT Q600, USA. Critical micelle concentration (CMC) was measured in oilfield water at room temperature using Du-Nouy tensiometer (KRUSS K6, Type 4851). All figures and tables concerning the characterization of the prepared gemini surfactants are included as ESI materials. $\dagger$

\subsection{Methodology}

2.4.1. Chemical measurements. Carbon steel specimens of dimensions $1 \times 0.9 \times 0.3 \mathrm{~cm}^{3}$ were prepared, weighed and then immersed in $50 \mathrm{ml}$ oilfield water solutions free and containing different concentrations of inhibitors for one week (168 h). After that, the specimens are removed from the electrolyte, corrosion products are removed and the specimens were washed with distilled water. Then, they are dried using a filter paper and reweighed using an analytical balance (model: Precisa 205 A, having a precision of $\pm 0.1 \mathrm{mg}$ ). The weight loss method is employed to calculate the corrosion rate $(\nu)$. The values of corrosion rate and inhibition efficiency $\left(E_{\mathrm{w}} \%\right)$ were calculated from eqn (1) and (2), respectively: ${ }^{19}$

$$
\begin{gathered}
\nu=\frac{\Delta w}{t \times A} \\
E_{\mathrm{w}} \%=\frac{\nu_{0}-\nu}{\nu_{0}} \times 100
\end{gathered}
$$

where $\nu_{\mathrm{o}}$ and $\nu$ are the corrosion rates $\left(\mathrm{mg} \mathrm{cm} \mathrm{cm}^{-2} \mathrm{~h}^{-1}\right)$ of carbon steel in oilfield water in absence and presence of inhibitors, respectively. $\Delta w$ is the weight loss of the specimen in mg. $A$ is the total surface area of specimens in $\mathrm{cm}^{2} . t$ is the immersion time in hours.

2.4.2. Electrochemical measurements. A three-electrode glass cell with a capacity of $100 \mathrm{ml}$ was used in all electrochemical experiments. A platinum sheet and a saturated calomel electrode (SCE) have served as counter and reference electrodes, respectively. The working electrode designed from carbon steel has a fixed surface area of $0.285 \mathrm{~cm}^{2}$ exposed to test solution. All electrochemical experiments were always carried out using the electrochemical work station IM6e Zahnerelectrik, Kronach, Germany, provided with Thales software. All electrochemical corrosion parameters were calculated using EC-Lab V10.40 corrosion software whilst EIS parameters were calculated using Thales Z1.28 Software. Before polarization and impedance experiments, open-circuit potential of the working electrode is measured with time till reaching a steady state value $\left(E_{\mathrm{ss}}\right)$ after about 30 minutes. EIS experiments were carried out at $E_{\mathrm{ss}}$ using a single sinusoidal perturbation signal of $10 \mathrm{mV}$ peak to peak amplitude while the frequency is changed over the range (100 kHz to $10 \mathrm{MHz}$ ).

In case of the electrochemical impedance spectroscopy, the corrosion inhibition efficiency $\left(E_{\mathrm{i}} \%\right)$ for all inhibitors was calculated from the value of the total resistance $\left(R_{\mathrm{t}}\right)$ of the metal surface $\left(R_{\mathrm{t}}=R_{\mathrm{f}}+R_{\mathrm{ct}}=R_{1}+R_{2}\right)$ obtained from EIS measurements, according to the following equation: ${ }^{20,21}$

$$
E_{\mathrm{i}} \%=\frac{R_{\mathrm{t}}-R_{\mathrm{t}(\mathrm{o})}}{R_{\mathrm{t}}} \times 100
$$

where $R_{\mathrm{t}(\mathrm{o})}$ and $R_{\mathrm{t}}$ is the total corrosion resistance of the metal surface in the absence and presence of inhibitors, respectively.

The potentiodynamic polarization measurements were carried out at a scan rate of $5 \mathrm{mV} \mathrm{s}^{-1}$ starting from -1 to $-0.4 \mathrm{~V}$ (vs. SCE). The inhibition efficiency $\left(E_{\mathrm{p}} \%\right)$ was determined using corrosion current density according to eqn (4): ${ }^{\mathbf{2 0 , 2 2}}$

$$
E_{\mathrm{p}} \%=\frac{I_{\text {corr }}^{\prime}-I_{\text {corr }}}{I_{\text {corr }}^{\prime}} \times 100
$$

where $I_{\text {corr }}^{\prime}$ and $I_{\text {corr }}$ are the uninhibited and the inhibited corrosion current densities, respectively. Corrosion parameters including corrosion current density $\left(I_{\text {corr }}\right)$, corrosion potential

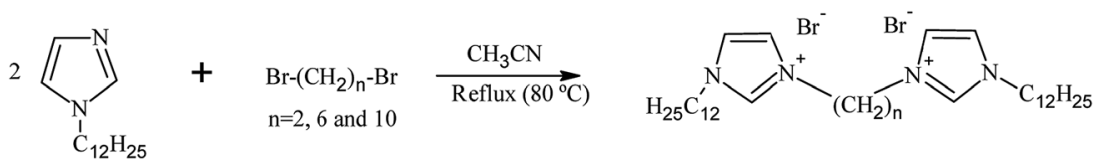

Scheme 2 Synthetic route for the three gemini surfactants (GS2, GS6 and GS10). 
$\left(E_{\text {corr }}\right)$, cathodic and anodic Tafel slopes $\left(\beta_{\mathrm{c}}\right.$ and $\left.\beta_{\mathrm{a}}\right)$ are obtained by extrapolating the linear parts of cathodic and anodic Tafel curves to the point of intersection..$^{20}$ The effect of temperature was studied using polarization technique throughout a temperature range of $283-313 \mathrm{~K}$. The potential of zero charge (pzc) is recorded as a relation between potential and capacitance giving a plot having a shape of a downward parabola whose minimum represents pzc. ${ }^{23}$ The potential is scanned over the range from -0.8 to $-0.6 \mathrm{~V}$ ( $v s$. SCE).

\subsection{Surface analysis}

2.5.1. SEM and EDX. Surface morphology of carbon steel immersed in blank and inhibited solutions of oilfield water is investigated using Scanning Electron Microscopy (SEM) and Energy Dispersive X-ray (EDX). Then, the surface morphology of carbon steel coupons is scanned using FE-SEM Model Quanta 250 attached with EDX (Energy Dispersive X-ray) unit, FEI Company, Netherlands.

2.5.2. FT-IR. FT-IR analysis is performed for corrosion products scratched from surface of C-steel immersed in inhibited solutions and compared with FT-IR spectra of crude inhibitors to confirm the occurrence of adsorption of inhibitors molecules on C-steel surface. ${ }^{24}$ FT-IR analysis was performed using $\mathrm{KBr}$ pellets via Perkin Elmer, Spectrum One FT-IR spectrometer.

\section{Results and discussion}

\subsection{Characterization of the synthesized gemini surfactants}

3.1.1. The intermediate compound. The mass spectrum of the intermediate compound (Fig. S1 $\dagger$ ) shows a base peak at $\mathrm{m} / z$ $=81.99\left[\left(\mathrm{C}_{3} \mathrm{~N}_{2} \mathrm{H}_{3}\right) \mathrm{CH}_{3}\right]^{+}$. and other significant peaks some of them are shown at $\mathrm{m} / \mathrm{z}: 68.98\left[\mathrm{CH}_{2} \mathrm{CHCH}_{2} \mathrm{CH}_{2} \mathrm{CH}_{2}\right]^{+}, 123.03$ $\left[\left(\mathrm{C}_{3} \mathrm{~N}_{2} \mathrm{H}_{3}\right) \mathrm{C}_{4} \mathrm{H}_{8}\right]^{+}, 136.92\left[\left(\mathrm{C}_{3} \mathrm{~N}_{2} \mathrm{H}_{3}\right) \mathrm{C}_{5} \mathrm{H}_{10}\right]^{+}, 151.03\left[\left(\mathrm{C}_{3} \mathrm{~N}_{2} \mathrm{H}_{3}\right)\right.$ $\left.\mathrm{C}_{6} \mathrm{H}_{12}\right]^{+}, 179.06\left[\left(\mathrm{C}_{3} \mathrm{~N}_{2} \mathrm{H}_{3}\right) \mathrm{C}_{8} \mathrm{H}_{16}\right]^{+}, 193.02\left[\left(\mathrm{C}_{3} \mathrm{~N}_{2} \mathrm{H}_{3}\right) \mathrm{C}_{9} \mathrm{H}_{18}\right]^{+}$, $207.07\left[\left(\mathrm{C}_{3} \mathrm{~N}_{2} \mathrm{H}_{3}\right) \mathrm{C}_{10} \mathrm{H}_{20}\right]^{+}$and $235.08\left[\left(\mathrm{C}_{3} \mathrm{~N}_{2} \mathrm{H}_{3}\right) \mathrm{C}_{12} \mathrm{H}_{24}\right]^{+}$. The molecular ion peak appears at $m / z$ of $236.13\left[\left(\mathrm{C}_{3} \mathrm{~N}_{2} \mathrm{H}_{3}\right) \mathrm{C}_{12} \mathrm{H}_{25}\right]^{+}$. Fig. S $2 \uparrow$ displays the FT-IR spectrum of the intermediate compound. Its FT-IR absorption bands are listed in Table S1† and can be discussed as following:

- Aliphatic C-H stretching bands appear at 2923-2854 $\mathrm{cm}^{-1}$.

- Aromatic C-H stretching bands appear at $3099 \mathrm{~cm}^{-1}$.

- $\mathrm{N}-\mathrm{H}$ stretching bands (broad) appear at $3407 \mathrm{~cm}^{-1}$. This could be attributed to the presence of the carbene proton in the form of $\mathrm{NH}^{+}$(Scheme $\mathrm{S} 1 \dagger$ ).

- $\mathrm{C}=\mathrm{C}$ stretching bands appear at $2028 \mathrm{~cm}^{-1}$.

- C-C stretching bands appear at $1563 \mathrm{~cm}^{-1}$.

Fig. $\mathrm{S} 3 \dagger$ demonstrates the $\mathrm{H}^{1}$-NMR spectrum of the intermediate compound. From the data listed in Table S2, $\dagger$ we can observe the following:

- The proton (a) has a high chemical shift which could be attributed to the presence of the carbene proton.

- The same protons (b) [with the value of $7.436 \mathrm{ppm}$ ], possesses the carbene type.
- The aromatic proton (c) has the value (6.969 ppm), whereas the aromatic protons (d) have the chemical shifts of $6.843 \mathrm{ppm}$. Both of the two types showed doublet spin multiplicity.

- Protons of the type (e), attached directly to nitrogen atom, have the value of 4.274 .

- In the case of protons (f), the chemical shift appears at 3.864 ppm.

- The $\delta$ value of $(\mathrm{g})$ protons is $1.703 \mathrm{ppm}$.

- In case of four protons (h), $\delta$ value is $1.187 \mathrm{ppm}$.

- The highly shielded protons of the monomer have the value of $0.812 \mathrm{ppm}$.

3.1.2. The gemini surfactants. The mass spectrum of GS2 (Fig. S4 $\dagger$ ) shows a base peak at $m / z=136.92\left[\left(\mathrm{C}_{3} \mathrm{~N}_{2} \mathrm{H}_{3}\right) \mathrm{C}_{5} \mathrm{H}_{10}\right]^{+}$ and other significant peaks some of them are shown at $m / z$ : $68.98\left[\mathrm{CH}_{2} \mathrm{CHCH}_{2} \mathrm{CH}_{2} \mathrm{CH}_{2}\right]^{+}, 81.99\left[\left(\mathrm{C}_{3} \mathrm{~N}_{2} \mathrm{H}_{3}\right) \mathrm{CH}_{3}\right]^{+}, \quad 123.03$ $\left[\left(\mathrm{C}_{3} \mathrm{~N}_{2} \mathrm{H}_{3}\right) \mathrm{C}_{4} \mathrm{H}_{8}\right]^{+}, \quad 151.03 \quad\left[\left(\mathrm{C}_{3} \mathrm{~N}_{2} \mathrm{H}_{3}\right) \mathrm{C}_{6} \mathrm{H}_{12}\right]^{+}, \quad 162.01$ $\left[\left(\mathrm{C}_{3} \mathrm{~N}_{2} \mathrm{H}_{3}\right)\left(\mathrm{CH}_{2}\right)_{2}\left[\left(\mathrm{C}_{3} \mathrm{~N}_{2} \mathrm{H}_{3}\right)\right]^{+}, 179.06\left[\left(\mathrm{C}_{3} \mathrm{~N}_{2} \mathrm{H}_{3}\right) \mathrm{C}_{8} \mathrm{H}_{16}\right]^{+}, 193.02\right.$ $\left[\left(\mathrm{C}_{3} \mathrm{~N}_{2} \mathrm{H}_{3}\right) \mathrm{C}_{9} \mathrm{H}_{18}\right]^{+}, 207.07\left[\left(\mathrm{C}_{3} \mathrm{~N}_{2} \mathrm{H}_{3}\right) \mathrm{C}_{10} \mathrm{H}_{20}\right]^{+}, 235.08\left[\left(\mathrm{C}_{3} \mathrm{~N}_{2} \mathrm{H}_{3}\right)\right.$ $\left.\mathrm{C}_{12} \mathrm{H}_{24}\right]^{+}$, and $236.13\left[\left(\mathrm{C}_{3} \mathrm{~N}_{2} \mathrm{H}_{3}\right) \mathrm{C}_{12} \mathrm{H}_{25}\right]^{+}$. The molecular ion peak appears at $m / z$ of $660\left[\mathrm{C}_{12} \mathrm{H}_{25}\left(\mathrm{C}_{3} \mathrm{~N}_{2} \mathrm{H}_{3}\right)_{2} \mathrm{C}_{12} \mathrm{H}_{25} \mathrm{Br}_{2}\right]^{+}$.

Fig. S5 through Fig. S7† display the FT-IR spectra of GS2, GS6 and GS10. The FT-IR absorption bands of the prepared gemini surfactants are listed in Table $\mathrm{S} 1 \dagger$ and can be discussed as following:

- N-H stretching bands (broad) appear at: $3417 \mathrm{~cm}^{-1}$; GS2, $3416 \mathrm{~cm}^{-1}$; GS6 and $3419 \mathrm{~cm}^{-1}$; GS10 due to the presence of the carbene proton in the form of $\mathrm{NH}^{+}$(Scheme 2).

- Aromatic C-H stretching bands appear at: $3039 \mathrm{~cm}^{-1}$ (GS2), $3073 \mathrm{~cm}^{-1}$ (GS6) and $3070 \mathrm{~cm}^{-1}$ (GS10).

- Aliphatic C-H stretching bands appear at: $2922-2852 \mathrm{~cm}^{-1}$ (GS2), 2924-2854 $\mathrm{cm}^{-1}$ (GS6) and 2923-2853 $\mathrm{cm}^{-1}$ (GS10).

- $\mathrm{C}=\mathrm{C}$ stretching bands appear at: $2042 \mathrm{~cm}^{-1}$ (GS2), $2062 \mathrm{~cm}^{-1}$ (GS6) and $2055 \mathrm{~cm}^{-1}$ (GS10).

- C-C stretching bands appear at: $1563 \mathrm{~cm}^{-1}$ (GS2), $1625 \mathrm{~cm}^{-1}$ (GS6) and $1623 \mathrm{~cm}^{-1}$ (GS10).

- $\mathrm{C}-\mathrm{Br}$ (ionic bond) bands appear at: $635.7 \mathrm{~cm}^{-1}$ (GS2), $634.9 \mathrm{~cm}^{-1}$ (GS6) and $634.8 \mathrm{~cm}^{-1}$ (GS10).

Fig. S8 through Fig. S10 $\dagger$ demonstrates the $\mathrm{H}^{1}$-NMR spectrum of GS2, GS6 and GS10. The chemical shifts of $\mathrm{H}^{1}$-NMR spectra for different types of protons in the three gemini surfactants (Fig. S11†) are listed in Table S3† and we can observe the following:

- The proton (a), [compounds GS2, GS6 and GS10], has high chemical shift (10.168, 10.177 and 10.323 ppm, respectively). This could be attributed also to the presence of the carbene proton in the form of $\mathrm{NH}^{+}$.

- The same protons (b) [with the values of 8.409, 9.375 and 9.274 ppm], possess the carbene type.

- The aromatic protons (c) have the values (7.376, 7.453 and $7.421 \mathrm{ppm}$ ), whereas the aromatic protons (d) have the chemical shifts of $7.270,7.272$ and $7.271 \mathrm{ppm}$. Both of the two types showed doublet spin multiplicity.

- Protons of the type (e), attached directly to $\mathrm{N}^{+}$, have the values of $4.534,4.308$ and 4.335 ppm respectively. The spin multiplicity of (e) proton is triplet.

- In case of compound GS2, the four protons (f) possess $(\delta)$ value of $4.202 \mathrm{ppm}$ (triplet). Whereas the four (f) protons of 
compounds GS6 and GS10 have the values of 4.248 and $3.370 \mathrm{ppm}$ with triplet spin multiplicity and the four ( $\mathrm{f}^{*}$ ) protons possess $(\delta)$ values of 4.283 and 3.393 ppm respectively with multiplet spin multiplicity.

- The $(\delta)$ value of the four multiplet ( $\mathrm{g}$ ) protons in (GS2) is $4.094 \mathrm{ppm}$. In the case of GS6 and GS10, the eight (multiplet g) protons are approximately equal and possess 3.462 and 2.568 ppm respectively.

- In case of four protons (h) of GS2 and GS6, $\delta$ values are 1.881 and 1.854 ppm respectively with multiplet spin multiplicity. While in GS10, the twelve protons possess $1.844 \mathrm{ppm}$ with multiplet multiplicity.

- The 32 protons (i) for GS2, GS6 and GS10 have the values of $1.273,1.383$ and $1.235 \mathrm{ppm}$ respectively, with multiplet multiplicity.

- The highly shielded six protons of GS2, GS6 and GS10, have the values of $0.838,0.811$ and $0.842 \mathrm{ppm}$ respectively with triplet spin multiplicity.

Table $\mathrm{S} 4 \dagger$ illustrates the results of elemental analysis where the observed results are in good agreement with the calculated ones. The thermal stability of the three prepared gemini surfactants was assessed using thermogravimetric analysis (TGA). Fig. S12 $\uparrow$ shows that the three surfactants are stable up to $250{ }^{\circ} \mathrm{C}$ and completely lose their weights at $340{ }^{\circ} \mathrm{C}$. Both GS6 and GS10 have comparable thermal stability but the gemini surfactant of shortest spacer (GS2) has showed a slight increase in the degradation temperature in comparison to both GS6 and GS10.

\subsection{Effect of inhibitor concentration}

3.2.1. Weight loss measurements. Gravimetric (chemical) method is utilized for evaluating the corrosion rate and inhibition efficiency $\left(E_{\mathrm{w}} \%\right)$ for carbon steel in oilfield water

Table 3 Weight loss rate and inhibition efficiency calculated from gravimetric measurements for $\mathrm{C}$-steel in oilfield water as a function of gemini surfactant concentration at room temperature for one week

\begin{tabular}{llll}
\hline Inhibitor & $\begin{array}{l}\text { Concentration } \\
(\mathrm{ppm})\end{array}$ & $\begin{array}{l}\text { Weight loss rate } \\
\times 10^{3}\left(\mathrm{mg} \mathrm{cm}^{-2} \mathrm{~h}^{-1}\right)\end{array}$ & $E_{\mathrm{w}} \%$ \\
\hline Blank & - & 5.30 & - \\
GS2 & 50 & 4.16 & 21.49 \\
& 100 & 1.98 & 62.69 \\
& 150 & 1.83 & 65.47 \\
& 200 & 1.72 & 67.64 \\
& 300 & 1.75 & 67.04 \\
GS6 & 400 & 1.75 & 67.05 \\
& 50 & 4.79 & 17.89 \\
& 100 & 3.46 & 34.76 \\
& 150 & 3.29 & 37.93 \\
& 200 & 3.12 & 41.13 \\
& 300 & 2.65 & 62.30 \\
GS10 & 400 & 3.02 & 43.05 \\
& 50 & 2.04 & 61.53 \\
& 100 & 0.85 & 83.98 \\
& 150 & 0.78 & 85.21 \\
& 200 & 0.85 & 81.96 \\
& 300 & 0.98 & 76.01
\end{tabular}

solutions in absence and presence of the three synthesized gemini surfactants, GS2, GS6 and GS10 at ambient temperature. Table 3 reveals that the corrosion rate of C-steel immersed in oilfield water containing GS2, GS6 or sGS10 decreases with increasing their concentration (up to critical values). This behavior can be attributed to the increase in the number of surfactant molecules adsorbed at metal/solution interface on increasing its concentration. So, molecules of the gemini surfactants constitute adsorption films on C-steel surface which protects it against corrosive species. The maximum $E_{\mathrm{w}} \%$ values for the three gemini surfactants are $67.64 \%$ at 200 ppm GS2, $62.30 \%$ at $300 \mathrm{ppm}$ GS6 and $85.21 \%$ at $150 \mathrm{ppm}$ GS10. The decrease in the corrosion rate of C-steel in oilfield water in presence of these gemini surfactants confirms that their molecules have adsorbed on C-steel surface. ${ }^{20}$

3.2.2. EIS measurements. EIS is an effective technique utilized for studying the corrosion behavior of protected and bare carbon steel. ${ }^{25}$ EIS spectra for solutions containing any gemini surfactant show some deviations from the ideal
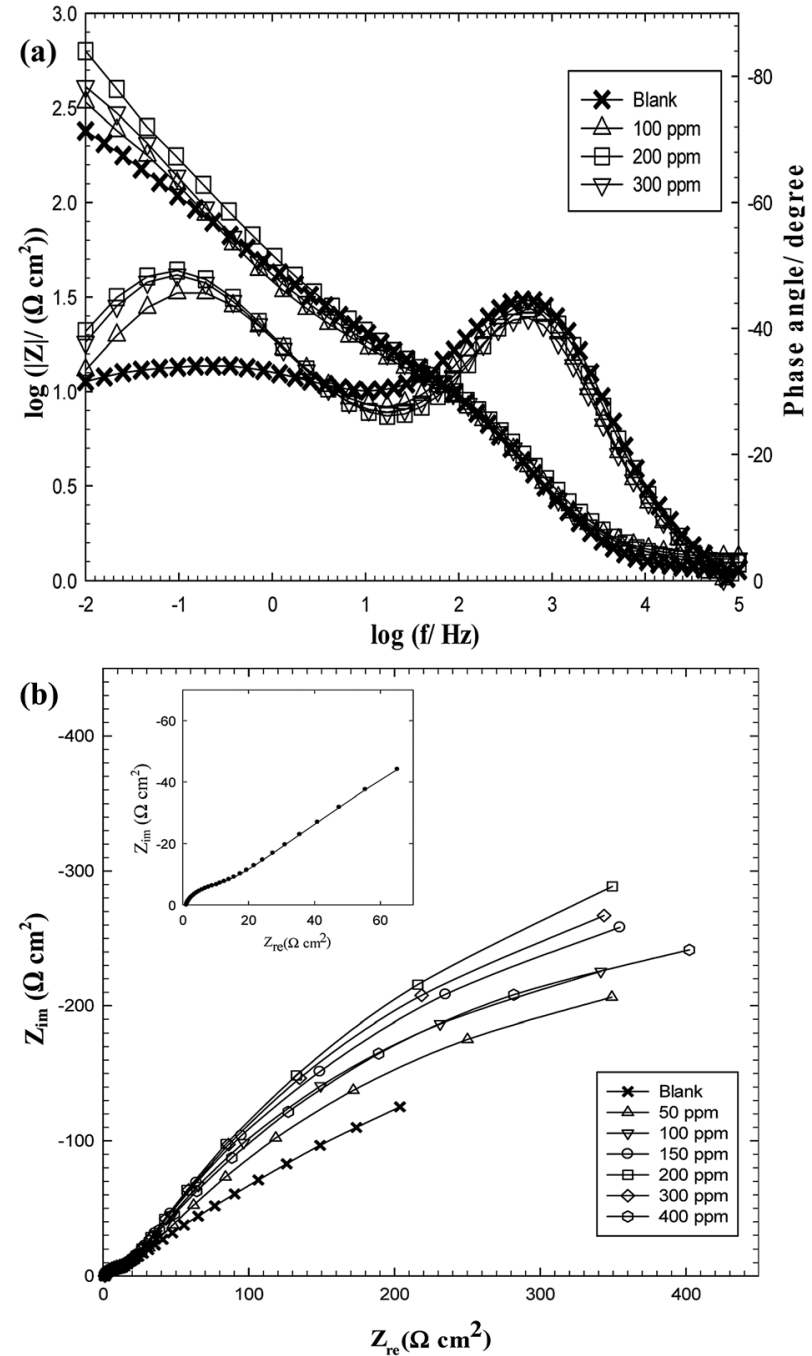

Fig. 2 EIS spectra for C-steel in oilfield water as a function of GS2 concentration at $293 \mathrm{~K}$ in the Bode format (a) and Nyquist format (b). 
capacitive behavior recorded in any tested solution. As an example, Bode plot for GS2 (Fig. 2(a)) displays a two-time constant behavior where the resistive part at LF region in Bode plot doesn't appear and $\Phi$ doesn't reach 0 although the spectra was measured down to $0.01 \mathrm{~Hz}$. Two-time constant behavior may be attributed to roughness and other inhomogeneity of solid surface. ${ }^{26}$ Moreover, Nyquist format (Fig. 2(b)) shows no ideal capacitive semicircles but each plot displays two incomplete semicircles: the first one, at high frequency (HF) region appearing as a part of small loop linked to another large incomplete one at low frequency region (LF) and deflects upward giving to a slightly inclined line or an arc. This feature refers to Warburg impedance ${ }^{21}$ due to diffusion process. ${ }^{27}$ For more clarification, Nyquist spectrum for the blank solution is displayed in the inset. The arcs that have appeared in the Nyquist plots represent parts of depressed semicircles whose centers are located beneath the real axis. This behavior is characteristic for solid electrodes and is often referred to as frequency dispersion and occurs due to surface roughness, impurities or dislocations. ${ }^{28}$ Surface roughness is attributed to the eating away of local sites on electrode surface. ${ }^{22}$ For oilfield

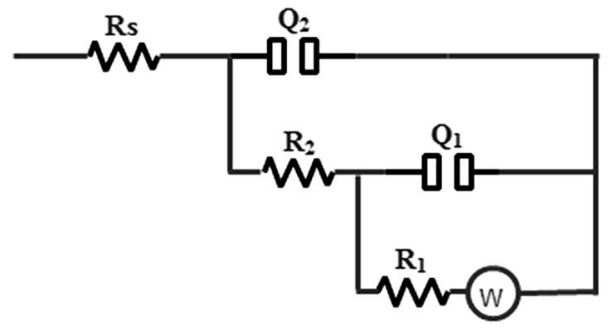

water inhibited by gemini surfactants, the straight line appearing at LF region in blank solution turns to take the shape of an arc whose angle increases with inhibitor concentration (till a critical value) due to the increase in the degree of surface coverage $(\theta)$ by inhibitor molecules. ${ }^{29}$ Above the critical concentrations, the arcs are lowered again indicating that corrosion protection has decreased again. EIS spectra for GS6 and GS10 are shown in ESI data (Fig. S13 through Fig. S16†).

In an attempt to analyze the experimental impedance data, the equivalent circuit depicted in Fig. $3^{30}$ was found to give a satisfactory fitting result with a maximum average error $0.3 \%$. In this electrical model, two constant phase elements $\left(Q_{1}\right.$ and $Q_{2}$ ) are used instead of the two real capacitances to give the best fitting. For a rough or porous surface, non-homogeneity can cause the double layer capacitance to appear as a constant phase element. ${ }^{31}$ This model consists of two-time constants $\left(\left(Q_{1} R_{1} W\right)\right.$ and $\left.\left(Q_{2} R_{2}\right)\right)$ parallel to each other and all in series to the solution resistance $\left(R_{\mathrm{S}}\right)$. The first time constant $\left(Q_{1} R_{1} W\right)$ expresses the behavior at $L F$ region and is attributed to the adsorbed film while the other one $\left(Q_{2} R_{2}\right)$ is related to the HF region and describes the behavior of the double layer at the base of pores or defects in the film. The constant phase element has a non-integer parameter called the phase shift ( $n$ ) which is used to compensate the system heterogeneity. So, the phase shift $(n)$ can be described as a degree of surface roughness or nonhomogeneity. ${ }^{32}$

Investigating the simulated data listed in Table 4 illustrates the following important points:

(a) The solution resistance $\left(R_{\mathrm{s}}\right)$ is low and nearly remains constant either in the absence or presence of inhibitors (ranges between 1.11 and $1.61 \Omega \mathrm{cm}^{2}$ ) due to good conductivity of all tested solutions. ${ }^{33}$

Fig. 3 The equivalent circuit.

Table 4 Electrochemical impedance parameters and inhibition efficiency calculated for C-steel in oilfield water as a function of gemini surfactant concentration at $293 \mathrm{~K}$

\begin{tabular}{|c|c|c|c|c|c|c|c|c|c|c|}
\hline Inhibitor & $C(\mathrm{ppm})$ & $\begin{array}{l}W \\
\left(\Omega \mathrm{cm}^{2} \mathrm{~s}^{-0.5}\right)\end{array}$ & $R_{1}\left(\Omega \mathrm{cm}^{2}\right)$ & $Q_{1}\left(\mu \mathrm{F} \mathrm{cm}^{-2}\right)$ & $n_{1}$ & $R_{2}\left(\Omega \mathrm{cm}^{2}\right)$ & $Q_{2}\left(\mu \mathrm{F} \mathrm{cm}^{-2}\right)$ & $n_{2}$ & $R_{\mathrm{s}}\left(\Omega \mathrm{cm}^{2}\right)$ & $E_{\mathrm{i}} \%$ \\
\hline Blank & - & 66.23 & 491.34 & 100.21 & 0.47 & 10.10 & 68.11 & 0.82 & 1.13 & - \\
\hline & 100 & 7.5 & 1056.21 & 252.32 & 0.585 & 12.41 & 71.44 & 0.815 & 1.29 & 53.08 \\
\hline & 150 & 7.21 & 1181.33 & 306.00 & 0.609 & 12.52 & 72.32 & 0.819 & 1.11 & 58.00 \\
\hline & 200 & 11.39 & 1726.53 & 314.21 & 0.601 & 11.39 & 69.02 & 0.819 & 1.20 & 71.15 \\
\hline GS6 & 50 & 150.08 & 654.08 & 62.67 & 0.42 & 17.12 & 51.75 & 0.804 & 1.29 & 25.29 \\
\hline & 100 & 27.87 & 802.85 & 104.14 & 0.484 & 13.47 & 47.65 & 0.753 & 1.35 & 38.57 \\
\hline & 150 & 128.14 & 993.23 & 118.91 & 0.498 & 13.86 & 50.98 & 0.777 & 1.57 & 50.21 \\
\hline & 200 & 1.85 & 1362.3 & 215.16 & 0.556 & 21.79 & 57.26 & 0.725 & 1.59 & 63.77 \\
\hline & 300 & 740.15 & 1393.65 & 132.04 & 0.501 & 15.04 & 45.65 & 0.749 & 1.16 & 64.40 \\
\hline & 400 & 2.62 & 1206.98 & 182.46 & 0.534 & 19.31 & 55.96 & 0.746 & 1.61 & 59.11 \\
\hline & 300 & 9.1 & 1633.34 & 161.19 & 0.62 & 25.95 & 48.25 & 0.8 & 1.33 & 69.78 \\
\hline & 400 & 48.22 & 1507.94 & 121.37 & 0.57 & 22.65 & 49.26 & 0.82 & 1.15 & 67.24 \\
\hline
\end{tabular}


(b) The resistance $\left(R_{1}\right)$ denoting to the resistance of the adsorbed film resistance $\left(R_{\mathrm{f}}\right)$ is generally with much higher values than those for $R_{2}$ representing the charge transfer resistance $\left(R_{\mathrm{ct}}\right) . R_{2}$ possesses a value of $10.01 \Omega \mathrm{cm}^{2}$ (in blank oilfield water) and slightly increases up to a maximum value of $14.25 \Omega \mathrm{cm}^{2}$ in presence of GS2, $21.79 \Omega \mathrm{cm}^{2}$ in presence of GS6 and $25.95 \Omega \mathrm{cm}^{2}$ in presence of GS10. So, the change in $R_{2}$ is not significant.

(c) Upon increasing the concentration of any gemini surfactant, a continuous significant increase in $R_{1}$ value is observed. In the blank solution, $R_{1}=491.34 \Omega \mathrm{cm}^{2}$ but $R_{1}$ increases to $1726.53 \Omega \mathrm{cm}^{2}$ (for oilfield water inhibited by $200 \mathrm{ppm}$ GS2), $1393.65 \Omega \mathrm{cm}^{2}$ (for solution inhibited by $300 \mathrm{ppm} \mathrm{GS6)}$ ) and $1951.40 \Omega \mathrm{cm}^{2}$ (for solution inhibited by $150 \mathrm{ppm}$ GS10). Above these concentrations, $R_{1}$ suffers a small decrease in its value.

(d) Comparing the values of the heterogeneity parameter $(n)$ indicates that $n_{1}<n_{2}$. The value of $n_{1}$ (relating to the adsorbed film) increases from 0.47 in the blank solution and reaches maximum values of $0.61,0.56$ and 0.62 in presence of GS2, GS6 and GS10, respectively. On the other hand, the values of $n_{2}$ (relating to the double layer at the metal/native film interface) nearly remains constant in all cases. These indications suggest that the C-steel surface contains voids and pores and the presence of gemini surfactants leads to reduction in surface roughness due to the adsorption of their molecules on adsorption sites of the C-steel surface. ${ }^{31}$

3.2.3. Potentiodynamic polarization measurements. Potentiodynamic polarization measurements can provide important information about the kinetics of cathodic and anodic corrosion reactions. ${ }^{20}$ Electrochemical corrosion parameters involve the corrosion potential $\left(E_{\text {corr }}\right)$, corrosion current density $\left(I_{\text {corr }}\right)$, as well as the anodic and cathodic Tafel constants $\left(\beta_{\mathrm{a}}\right.$ and $\left.\beta_{\mathrm{c}}\right)$, respectively. These parameters were derived from Tafel polarization curves $(E-\log I)$ for carbon steel immersed in oilfield water solutions in the absence and presence of gemini surfactants and their values are listed in Table 5 . As an example, Tafel curves of GS2 are shown in Fig. 4. Tafel curves for GS6 and GS10 are presented in ESI materials (Fig. S17 and $S 18, \dagger$ respectively). $I_{\text {corr }}$ values are obtained from the intersection between the extrapolations of linear regions of the anodic and cathodic branches in the Tafel polarization plot provided that the intersection point corresponds to $E_{\text {corr }}$ (the potential at which $I_{\text {corr }}$ is minimum) ${ }^{34}$ Investigating Table 5 yields the following information:

(1) $I_{\text {corr }}$ values decrease with the increase in concentrations of gemini surfactants till their critical values (200 ppm for GS2, $300 \mathrm{ppm}$ for GS6 and $150 \mathrm{ppm}$ for GS10). After that, $I_{\text {corr }}$ reincreases again because the surface becomes slightly bare and vulnerable to corrosion attack.

(2) For GS2, the maximum displacement in $E_{\text {corr }}$ is about $-22 \mathrm{mV}$ relative to $E_{\text {corr }}$ recorded in the blank solution. For GS6, the maximum $E_{\text {corr }}$ displacement is about $-65 \mathrm{mV}$, while GS10 shows a maximum displacement in $E_{\text {corr }}$ of about $+10 \mathrm{mV}$. By convention, if the magnitude of $E_{\text {corr }}$ displacement in the presence of inhibitor is $> \pm 85 \mathrm{mV}$ with respect to $E_{\text {corr }}$ in blank solution, the inhibitor is classified as cathodic or anodic-type
Table 5 Electrochemical corrosion parameters and inhibition efficiency calculated for $\mathrm{C}$-steel in oilfield water as a function of gemini surfactant concentration at $293 \mathrm{~K}$

\begin{tabular}{lllllll}
\hline Inhibitor & $\begin{array}{l}\text { Conc. } \\
(\mathrm{ppm})\end{array}$ & $\begin{array}{l}I_{\text {corr }} \\
\left(\mu \mathrm{A} \mathrm{cm}^{-2}\right)\end{array}$ & $\begin{array}{l}E_{\text {corr }} \\
(\mathrm{V})\end{array}$ & $\begin{array}{l}\beta_{\mathrm{a}} \\
\left(\mathrm{V} \mathrm{dec}^{-1}\right)\end{array}$ & $\begin{array}{l}\beta_{\mathrm{c}} \\
\left(\mathrm{V} \mathrm{dec}^{-1}\right)\end{array}$ & $E_{\mathrm{p}} \%$ \\
\hline \multirow{2}{*}{ Blank } & - & 95.37 & -0.825 & 0.185 & -0.107 & - \\
& 50 & 52.42 & -0.836 & 0.175 & -0.123 & 45.03 \\
& 100 & 45.39 & -0.831 & 0.145 & -0.112 & 52.41 \\
& 150 & 37.28 & -0.844 & 0.127 & -0.098 & 60.91 \\
& 200 & 28.67 & -0.847 & 0.090 & -0.084 & 69.93 \\
& 300 & 31.34 & -0.842 & 0.107 & -0.091 & 67.14 \\
GS6 & 400 & 32.20 & -0.828 & 0.134 & -0.101 & 66.24 \\
& 50 & 67.93 & -0.861 & 0.195 & -0.113 & 28.77 \\
& 100 & 56.64 & -0.872 & 0.175 & -0.099 & 40.61 \\
& 150 & 43.12 & -0.878 & 0.140 & -0.086 & 54.79 \\
& 200 & 35.98 & -0.880 & 0.126 & -0.077 & 62.28 \\
& 300 & 35.31 & -0.890 & 0.108 & -0.070 & 62.98 \\
GS10 & 400 & 36.58 & -0.887 & 0.047 & -0.039 & 61.65 \\
& 50 & 34.27 & -0.823 & 0.161 & -0.122 & 64.06 \\
& 100 & 26.22 & -0.823 & 0.164 & -0.123 & 72.51 \\
& 150 & 18.36 & -0.821 & 0.118 & -0.105 & 80.75 \\
& 200 & 23.26 & -0.815 & 0.147 & -0.125 & 75.61 \\
& 300 & 24.34 & -0.822 & 0.169 & -0.128 & 74.47 \\
& 400 & 28.88 & -0.817 & 0.176 & -0.134 & 69.71 \\
& & & & & & \\
\hline
\end{tabular}

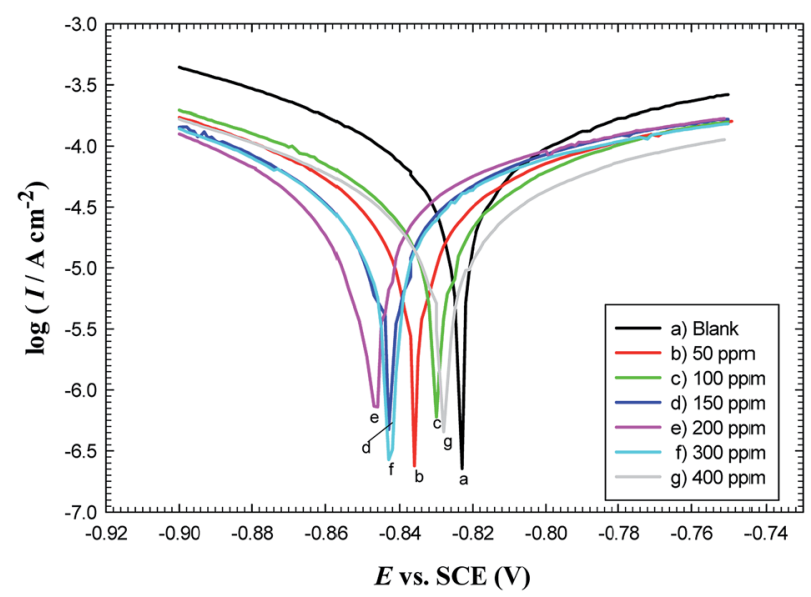

Fig. 4 Polarization curves for carbon steel in oilfield water as a function of GS2 concentration at $293 \mathrm{~K}$.

inhibitor according to the direction of the potential shift either to the more negative or to the more positive direction, respectively. If the displacement in $E_{\text {corr }}$ is $<85 \mathrm{mV}$, the inhibitor can be classified as a mixed-type inhibitor. ${ }^{20}$ So, GS2 and GS6 are mixed-type inhibitors with major cathodic effectiveness, while GS10 is a mixed type inhibitor but with a predominant anodic effect.

(3) Both anodic and cathodic Tafel slopes $\left(\beta_{\mathrm{a}}\right.$ and $\left.\beta_{\mathrm{c}}\right)$ are changed significantly for all gemini surfactants which confirms that these inhibitors affect mechanisms of both cathodic and anodic reactions (they belong to mixed-type inhibitors), ${ }^{35}$ where the displacement in the values of Tafel slopes is attributed to a change in reaction mechanism. ${ }^{20}$ 
The inhibition efficiency values increase as a function of concentration of gemini surfactants till certain values. Above these critical concentrations, the inhibition efficiency values start to decrease again with increasing concentration. There are two suggestions for explaining this behavior:

$1 \mathrm{Mu}$ et $a l^{36}$ have studied the inhibitive effect of sodium dodecyl sulfonate (SDS) on mild steel in $2 \mathrm{M} \mathrm{HCl}$ and found that the maximum inhibition efficiency was obtained at $150 \mathrm{ppm}$ and the inhibition efficiency decreases when surfactant concentration increases above this value. They explained this behavior in a manner that at the high concentration range, SDS adsorbed on the steel surface may form hemi-micelles through the interaction between their hydrophobic groups and these hemi-micelles are similar in structure to the normal micelles. According to this attitude, high concentrations of gemini surfactants lead to aggregation of their molecules which may lead to the desorption of some initially adsorbed ones.

2 Jiang et al. ${ }^{37}$ have proposed another mechanism for the decrease in the inhibition efficiency values above an optimum or a critical concentration based on the adsorption mode of surfactant molecules on steel surface as follows (Fig. 5):

(a) Below or at the optimum concentration surfactant molecules adsorb on steel surface in a parallel position (with respect to $\mathrm{C}$-steel surface). As the surfactant concentration increases, more surfactant molecules adsorb on the steel surface leading to covering more active sides on the steel surface. When concentration reaching the optimum value, steel surface becomes covered with surfactant molecules to its maximum extent (Fig. 5(b)). (b) Above the optimum concentration, the number of surfactant molecules becomes so much that electrostatic interactions between them force the initially adsorbed molecules (in their parallel position) to change their mode of adsorption to allow more number of molecules to adsorb on the metal surface. So, gemini surfactant molecules adsorb on the surface in a perpendicular position (with respect to C-steel surface) to permit steel surface to be attached to more and more surfactant molecules. Accordingly, the surface area occupied by surfactant molecules, despite their huge number, becomes lower than before. So, corrosive species have the chance again to attack the steel surface and hence the corrosion rate increases again (Fig. 5(c)).

3.2.4. Surface tension measurements. Generally, the relationship between the surface tension and the concentration added from each tested gemini surfactant (Fig. S19†) reveals an initial sharp decrease in the surface tension of the oilfield water solution. This is followed by a slighter decrease in the surface tension value as the GS concentration is further increased which ends finally with a plateau. Just at the beginning of this plateau the critical micelle concentration (CMC) is attained. CMC is the lowest concentration at which micelles (surfactant aggregations) begin to form. When micelles are formed, the repulsion forces between the head groups of surfactant molecules constructing the micelle are balanced by hydrophobic attractions between chains. For ionic micelles, these forces are balanced also by attractions between head groups and counter ions. ${ }^{15}$ Herein, CMC values for GS2, GS6 and GS10 are approximately 300, 300 and 200 ppm, respectively. It is obvious that the

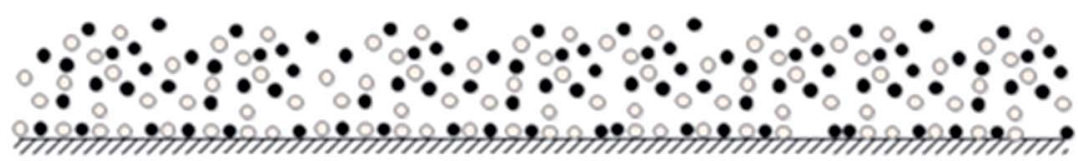

a) Oilfield water free from inhibitors

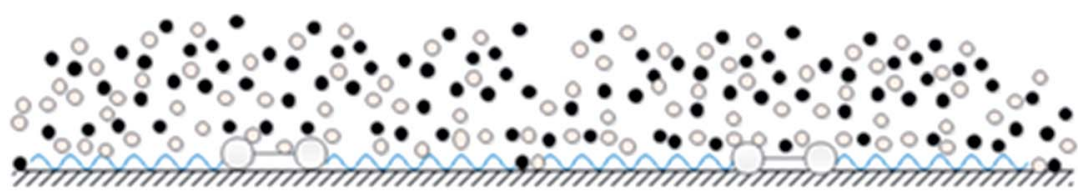

b) Oilfield water + Gemini surfactant ( $\leq$ critical concentration)

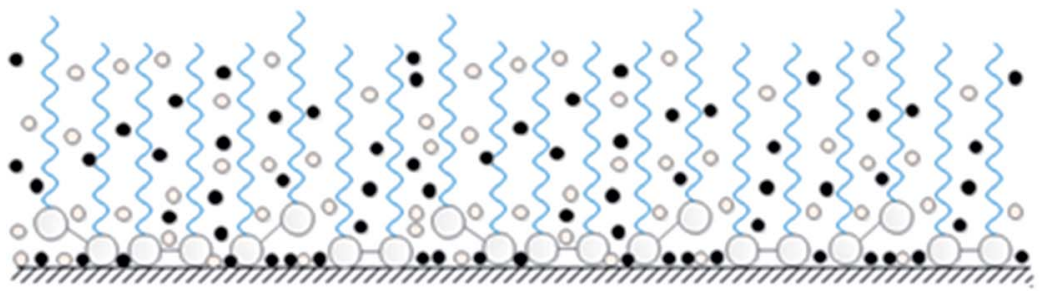

c) Oilfield water + Gemini surfactant $(>$ critical concentration)

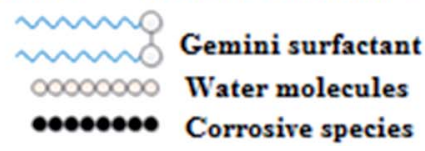

Fig. 5 Adsorption mechanism of gemini surfactant on carbon steel surface. 
maximum inhibition efficiency is below or just at the CMC values at which micelles begin to form. After CMC, the inhibition efficiency decreases as surfactant molecules start to leave the carbon steel surface offering a chance for the corrosive species to re-attack the bare region on the steel surface.

3.2.5. Adsorption isotherms. Since the metal surface in aqueous solutions is always covered with adsorbed water molecules, the adsorption of inhibitor molecules from the aqueous solution can be considered as a quasi-substitution process between the inhibitor molecules in the aqueous phase, $\operatorname{Inh}_{(\text {sol) }}$, and the water molecules at the metal surface, $\mathrm{H}_{2} \mathrm{O}_{(\text {ads })}:^{38}$

$$
\mathrm{Inh}_{(\mathrm{sol})}+x \mathrm{H}_{2} \mathrm{O}_{(\mathrm{ads})} \rightarrow \mathrm{Inh}_{(\mathrm{ads})}+x \mathrm{H}_{2} \mathrm{O}_{(\mathrm{sol})}
$$

where $x$ represents the number of water molecules replaced by one molecule of organic inhibitor. Corrosion inhibition is a surface process based on the adsorption of organic compounds on the metal surface. ${ }^{39}$ The presence of chemically stable and surface active inhibitor molecules increases the energy of activation for iron dissolution reaction and leads to diminishing its surface area available for corrosion attack. ${ }^{40}$

The mechanism of corrosion inhibition can be thus explained on the basis of adsorption principle ${ }^{41}$ and the nature of the interaction between the inhibitor and C-steel surface can be understood using an adsorption isotherm. ${ }^{42}$ Assuming that the gemini surfactants reduce the rate of corrosion process mainly through the increase in the degree of C-steel surface coverage $(\theta)$ by surfactant molecules, the inhibition efficiency can be considered as a function of $\theta$, i.e. $\theta=10^{-2} \times E \% .^{22}$ Frumkin, Freundlich, Temkin, Flory-Huggins and Langmuir adsorption isotherms have been attempted for fitting the adsorption of molecules of GS2, GS6 and GS10 on C-steel surface in oilfield water. It was found that the Langmuir model have showed the best fitting where it had the highest values of regression factor, $r^{2}$. Langmuir isotherm is represented with a relation between $\frac{C}{\theta}$ and $C$ according to eqn (6): ${ }^{\mathbf{4 0 , 4 3}}$

$$
\frac{C}{\theta}=\frac{1}{K_{\mathrm{ads}}}+C
$$

where $K_{\text {ads }}$ is the adsorption-desorption equilibrium constant. Langmuir isotherm assumes that the solid surface contains a fixed number of adsorption sites and each site holds one adsorbed species $^{22}$ and there are no interactions between the adsorbed molecules on the metal surface. ${ }^{40}$ Langmuir plot is drawn based on the data obtained from weight loss, EIS and polarization techniques (Fig. 6) and the change in free energy of adsorption $\left(\Delta G_{\mathrm{ads}}\right)$ is calculated according to the following equation: ${ }^{44}$

$$
\Delta G_{\mathrm{ads}}=-R T \ln \left(10^{6} K_{\mathrm{ads}}\right)
$$

where the factor $10^{6}$ represents the concentration of water molecules in the solution (in $\mathrm{mg}^{-1}$ ) and $R$ is the universal gas constant (8.314 $\mathrm{J} \mathrm{K}^{-1} \mathrm{~mol}^{-1}$ ). $\Delta G_{\text {ads }}$ values are depicted in Table 6. The value of $\Delta G_{\text {ads }}$ determines the nature of adsorption process such that: (i) if $\Delta G_{\text {ads }}$ is less negative than $-20 \mathrm{~kJ} \mathrm{~mol}^{-1}$
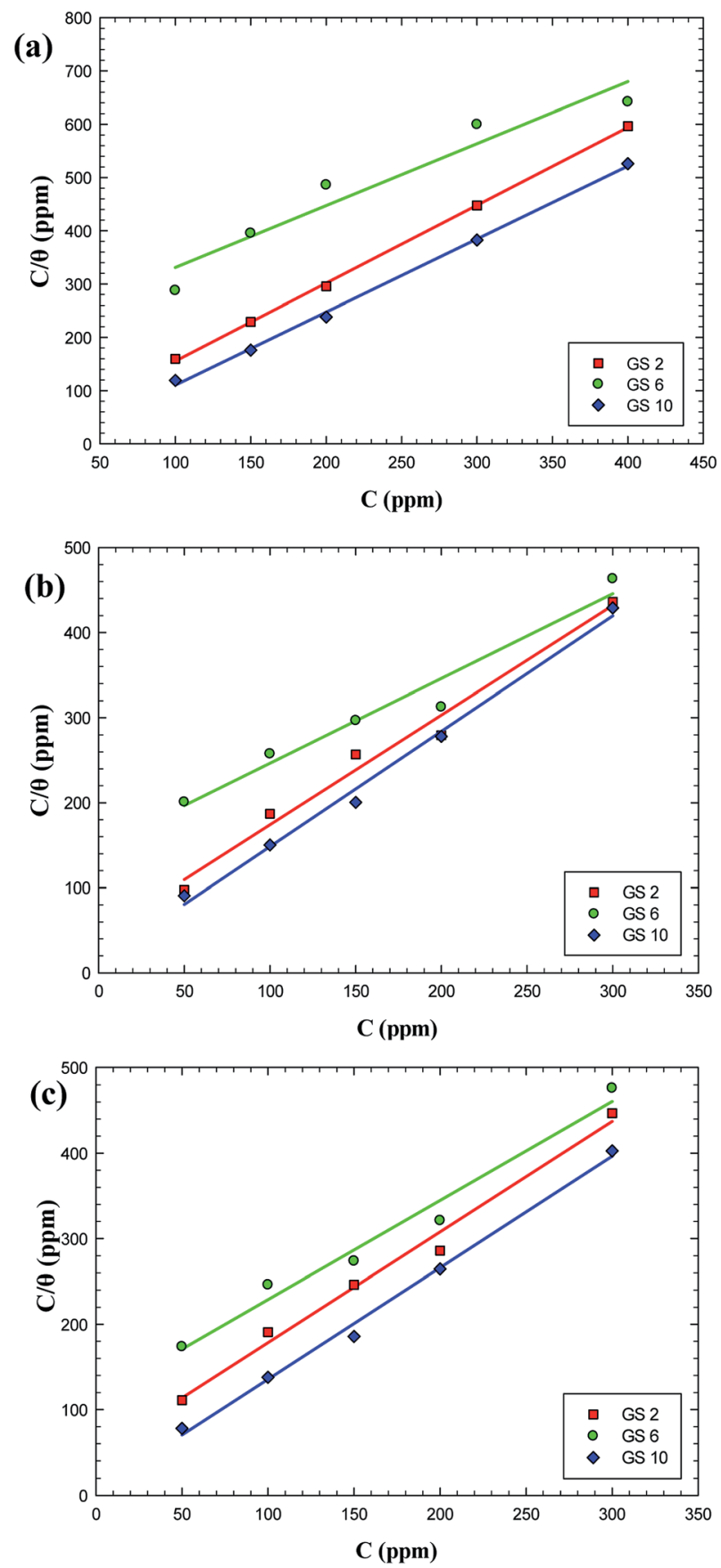

Fig. 6 Langmuir adsorption plots for carbon steel in oilfield water inhibited by gemini surfactants based on data from weight loss (a), EIS (b) and polarization (c).

the adsorption will be physical (known as physisorption) which occurs via electrostatic interactions. (ii) If $\Delta G_{\text {ads }}$ is more negative than $-40 \mathrm{~kJ} \mathrm{~mol}^{-1}$ the adsorption is chemical (known as chemisorption) where coordinate bonds are formed via electron transfer from inhibitor molecules to the metal surface. (iii) But, if the $\Delta G_{\text {ads }}$ is between -20 and $-40 \mathrm{~kJ} \mathrm{~mol}^{-1}$ then both types of adsorption are involved..$^{38}$ For GS2, GS6 and GS10, $\Delta G_{\text {ads }}$ values are ranging between -20.58 and $-30.44 \mathrm{~kJ} \mathrm{~mol}^{-1}$ which indicate the occurrence of both physisorption and chemisorption processes 
Table 6 Langmuir adsorption parameters for the adsorption of gemini surfactants on C-steel surface in oilfield water at $293 \mathrm{~K}$

\begin{tabular}{lllll}
\hline \multirow{2}{*}{ Inhibitor } & Technique & $r^{2}$ & $K_{\mathrm{ads}}\left(\mathrm{ppm}^{-1}\right)$ & $\begin{array}{l}\Delta G \\
\left(\mathrm{~kJ} \mathrm{~mol}^{-1}\right)\end{array}$ \\
\hline \multirow{2}{*}{ GS2 } & Weight loss & 0.9995 & 0.107 & -28.20 \\
& EIS & 0.9806 & 0.022 & -24.39 \\
& Tafel polarization & 0.9882 & 0.020 & -24.17 \\
GS6 & Weight loss & 0.9271 & 0.005 & -20.58 \\
& EIS & 0.9591 & 0.007 & -21.50 \\
\multirow{3}{*}{ GS10 } & Tafel polarization & 0.9793 & 0.009 & -22.14 \\
& Weight loss & 0.9877 & 0.267 & -30.44 \\
& EIS & 0.9930 & 0.079 & -27.47 \\
& Tafel polarization & 0.9947 & 0.195 & -29.67 \\
\hline
\end{tabular}

with the predominance of the former mode. ${ }^{45}$ The negative values of $\Delta G_{\text {ads }}$ for adsorption of all gemini surfactants on C-steel implies the spontaneity and stability of adsorption process. ${ }^{46}$

\subsection{Effect of temperature}

The effect of temperature on corrosion rates of C-steel and its impact on the stability of the protective film in oilfield water in the absence and presence of gemini surfactants were studied electrochemically using the potentiodynamic polarization method over the temperature range 283-313 K. Fig. 7 reveals that the C-steel potential either in the blank or inhibited solutions is shifted towards more negative values with time and the $E_{\mathrm{ss}}$ value is shifted also towards the more negative direction as temperature increases but the shift in $E_{\mathrm{ss}}$ value is more significant for blank solution than in the presence of inhibitors. This could be attributed to the effect of adsorption layer which can slightly isolate the C-steel surface from the corrosive medium. Fig. 8 shows that the magnitude of corrosion current density $\left(I_{\text {corr }}\right)$ increases as temperature is raised either for the inhibited or uninhibited solutions of oilfield water. Nevertheless, Table 7 reveals that the change in $I_{\text {corr }}$ between 283 and $313 \mathrm{~K}$ in oilfield water solutions containing GS2, GS6 or GS10 is small $(\sim 31,26$ and $26 \mu \mathrm{A} \mathrm{cm}{ }^{-2}$, respectively) in comparison to that of blank oilfield water $\left(\sim 51 \mu \mathrm{A} \mathrm{cm}^{-2}\right)$ which could be also related to the isolating effect of adsorption films of gemini surfactants. The rate of change in $E_{\mathrm{ss}}$ is coincident with the rate of change in $I_{\text {corr }}$ which confirms that adsorption films maintain their stability and protective effect even at elevated temperatures.

Thermodynamic activation parameters have an important role in understanding the inhibitive mechanism of organic additives. ${ }^{22}$ The apparent activation energy associated with Csteel corrosion in free and inhibited solutions of oilfield water was determined using Arrhenius plot (Fig. 9(a)) according to the following equation: ${ }^{24}$

$$
I_{\text {corr }}=A \mathrm{e}^{\left(-E_{\mathrm{a}} / \mathrm{RT}\right)}
$$

where $E_{\mathrm{a}}$ is the apparent activation energy, $A$ is Arrhenius factor, $T$ is the absolute temperature and $R$ is the universal gas constant. Table 8 shows that the apparent activation energy $\left(E_{\mathrm{a}}\right)$ obtained from Arrhenius plots has increased for solutions of oilfield water inhibited by GS2, GS6 and GS10 from
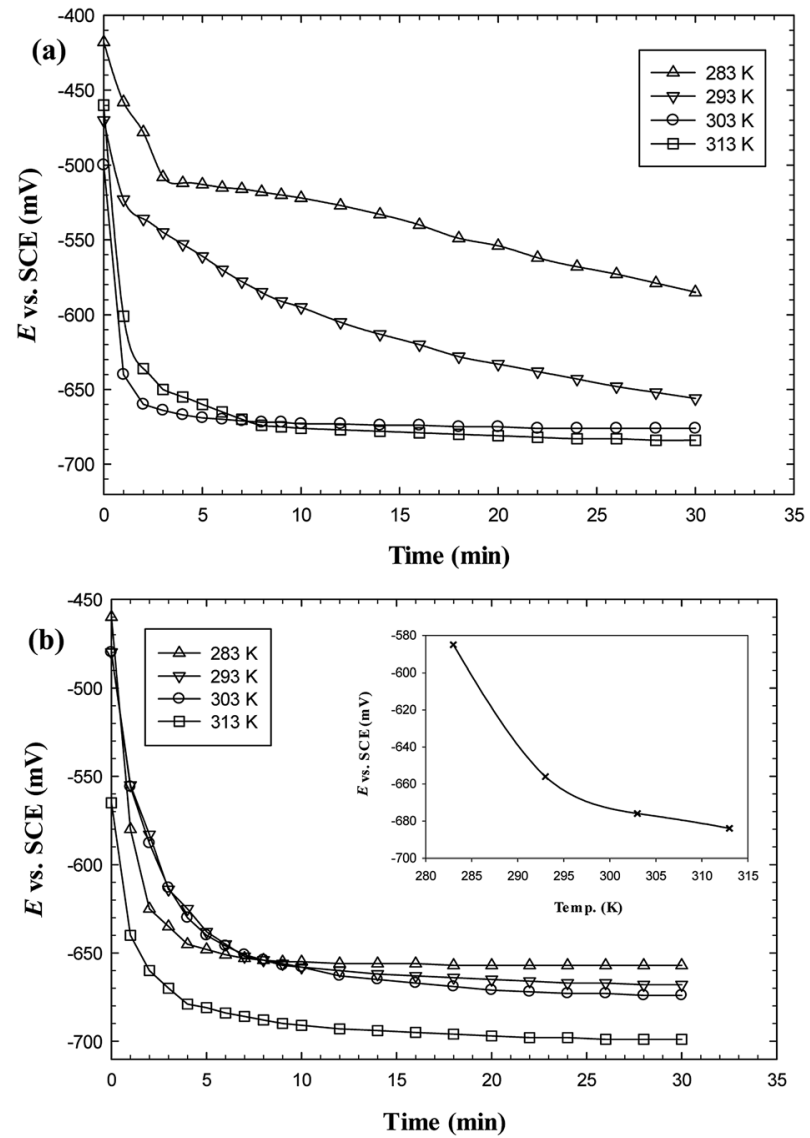

Fig. 7 Variation of C-steel potential in oilfield water free from inhibitors (a) and containing 300 ppm GS2 (b) with time at different temperatures. Inset: change in $E_{\mathrm{ss}}$ of $\mathrm{C}$-steel in oilfield water with temperature.

$13.59 \mathrm{~kJ} \mathrm{~mol}^{-1}$ (in blank oilfield water) to $22.37,17.70$ and $24.92 \mathrm{~kJ} \mathrm{~mol}^{-1}$, respectively. This indicates that the energy barrier for the corrosion reaction has been raised and hence the corrosion inhibition is enhanced. ${ }^{47} E_{\mathrm{a}}$ values for solutions of oilfield water inhibited by GS2 and GS10 are over $20 \mathrm{~kJ} \mathrm{~mol}^{-1}$ indicating that the inhibition process is under surface reaction control. $^{22}$

Analysis of the dependence of inhibition efficiency on temperature as well as the comparison of corrosion activation energies in the absence and presence of an inhibitor give useful information about the mechanism of inhibitor adsorption. Upon elevating the ambient temperature a simultaneous decrease in the inhibition efficiency together with a concurrent increase in corrosion activation energy $\left(E_{\mathrm{a}}\right)$ in presence of inhibitor compared to its absence confirms the formation of an adsorption film of physical nature (electrostatic). On the other hand, the increase in inhibition efficiency with raising temperature accompanied with a decrease in activation energy in the presence of inhibitor suggests a chemisorption mechanism. ${ }^{48}$ Physical adsorption arises by electrostatic interaction, while chemical adsorption occurs through a bond formation by sharing an electron. ${ }^{49}$ So, these gemini surfactants adsorb mainly via physical adsorption on C-steel surface. 

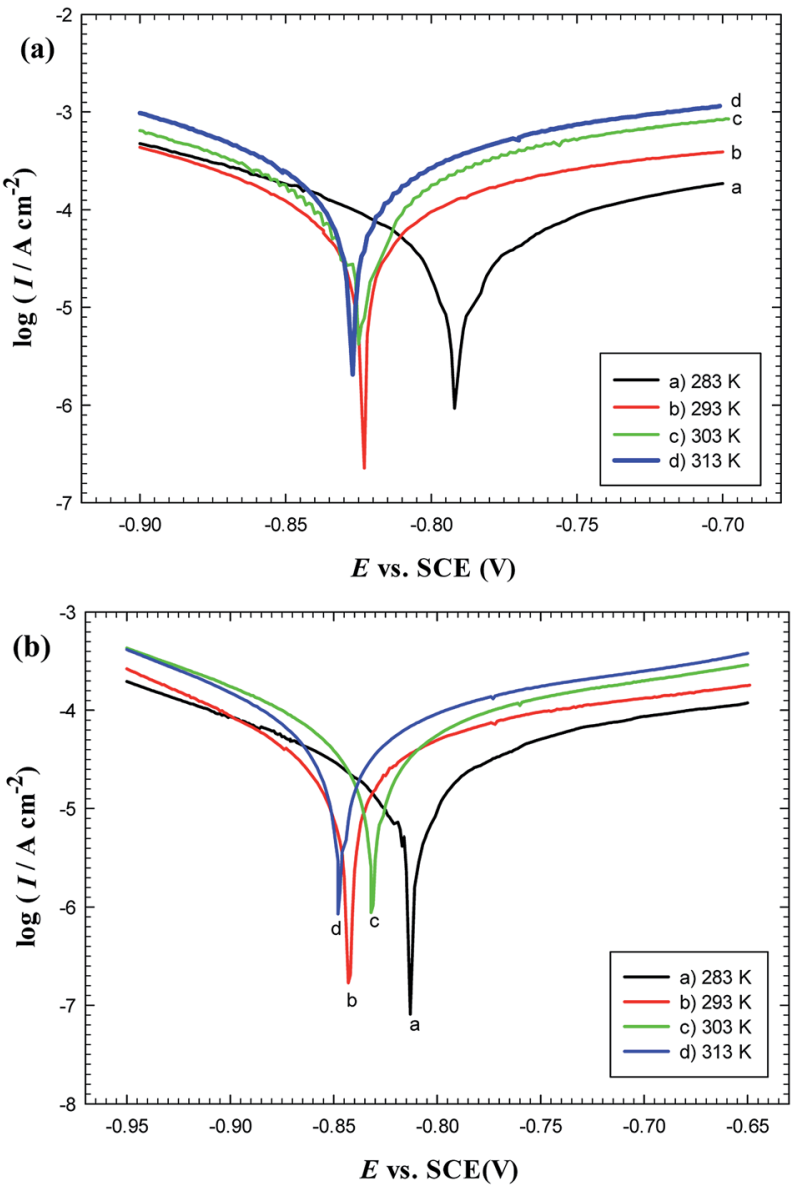

Fig. 8 Polarization curves for carbon steel in oilfield water free (a) and containing 300 ppm GS2 (b) at different temperatures.

Table 7 Corrosion kinetic parameters for carbon steel in oilfield water in absence and presence of 300 ppm of each gemini surfactant as a function of temperature

\begin{tabular}{|c|c|c|c|c|c|c|}
\hline Inhibitor & $\begin{array}{l}\text { Temperature } \\
\text { (K) }\end{array}$ & $\begin{array}{l}I_{\text {corr }} \\
\left(\mu \mathrm{Acm}^{-2}\right)\end{array}$ & $\begin{array}{l}E_{\text {corr }} \\
(\mathrm{V})\end{array}$ & $\begin{array}{l}\beta_{\mathrm{a}} \\
\left(\mathrm{V} \text { dec. }{ }^{-1}\right)\end{array}$ & $\begin{array}{l}\beta_{\mathrm{c}} \\
\left(\mathrm{V} \text { dec. }{ }^{-1}\right)\end{array}$ & $E_{\mathrm{p}} \%$ \\
\hline \multirow[t]{4}{*}{ Blank } & 283 & 63.58 & -0.793 & 0.239 & -0.132 & - \\
\hline & 293 & 95.37 & -0.824 & 0.185 & -0.107 & - \\
\hline & 303 & 101.05 & -0.825 & 0.135 & -0.121 & - \\
\hline & 313 & 114.70 & -0.827 & 0.057 & -0.569 & - \\
\hline \multirow[t]{4}{*}{ GS2 } & 283 & 20.00 & -0.813 & 0.158 & -0.139 & 68.54 \\
\hline & 293 & 31.34 & -0.842 & 0.129 & -0.099 & 67.14 \\
\hline & 303 & 38.78 & -0.831 & 0.128 & -0.096 & 61.62 \\
\hline & 313 & 51.09 & -0.847 & 0.171 & -0.112 & 54.20 \\
\hline \multirow[t]{4}{*}{ GS6 } & 283 & 23.51 & -0.811 & 0.139 & -0.109 & 63.02 \\
\hline & 293 & 35.31 & -0.890 & 0.108 & -0.070 & 62.98 \\
\hline & 303 & 42.11 & -0.848 & 0.153 & -0.102 & 58.33 \\
\hline & 313 & 49.12 & -0.815 & 0.079 & -0.082 & 57.17 \\
\hline \multirow[t]{4}{*}{ GS10 } & 283 & 14.71 & -0.809 & 0.131 & -0.117 & 76.87 \\
\hline & 293 & 24.34 & -0.822 & 0.169 & -0.128 & 74.47 \\
\hline & 303 & 34.27 & -0.806 & 0.174 & -0.134 & 66.09 \\
\hline & 313 & 40.24 & -0.802 & 0.169 & -0.141 & 64.91 \\
\hline
\end{tabular}

Thermodynamic parameters of activation, enthalpy change $\left(\Delta H^{*}\right)$ and entropy change $\left(\Delta S^{*}\right)$, were calculated from eqn (9) using $\log \left(\frac{I_{\text {corr }}}{T}\right)$ vs. $T$ plot (Fig. 9(b)) where its slope equals
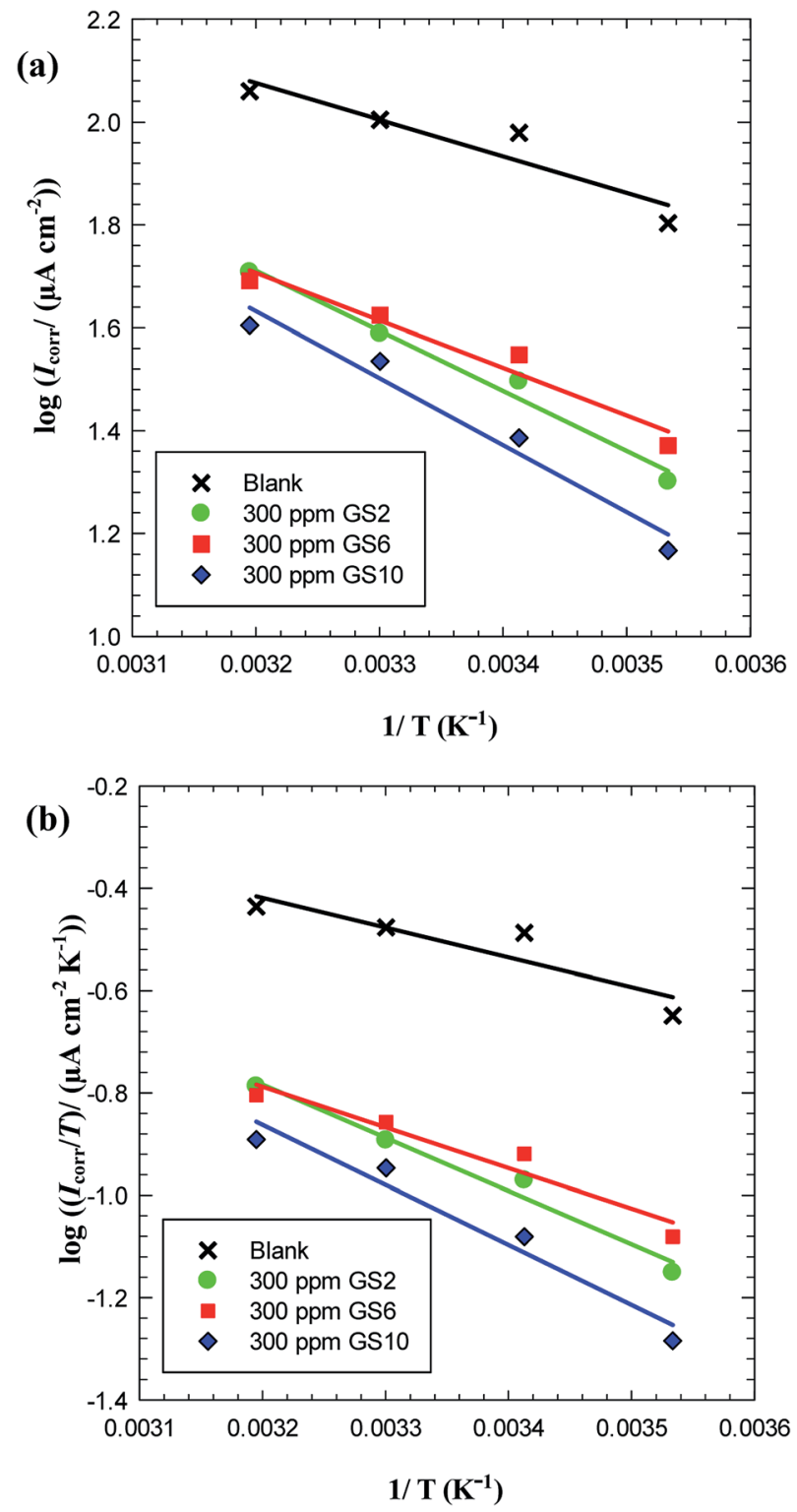

Fig. 9 Arrhenius plot (a) and transition state plot (b) for carbon steel in oilfield water in absence and presence of GS2, GS6 and GS10.

$\frac{-\Delta H^{*}}{2.303 R}$ and its intercept represents $\left(\log \frac{R}{N_{\mathrm{A}} h}+\frac{\Delta S^{*}}{2.303 R}\right)$ where $h$ is Planck's constant $\left(6.626 \times 10^{-34} \mathrm{~J} \mathrm{~s}\right), N_{\mathrm{A}}$ is Avogadro's number $\left(6.022 \times 10^{23} \mathrm{~mol}^{-1}\right), R$ is the general gas constant $\left(8.314 \mathrm{~J} \mathrm{~K}^{-1} \mathrm{~mol}^{-1}\right){ }^{24}$

$$
\log \left(\frac{I_{\text {corr }}}{T}\right)=\log \frac{R}{N_{\mathrm{A}} h}-\frac{\Delta H^{*}}{2.303 R T}+\frac{\Delta S^{*}}{2.303 R}
$$

The $\Delta H^{*}$ values of activation for the dissolution reaction of C-steel surface in oilfield water in the presence of GS2, GS6 and GS10 are high (19.89, 15.22 and $22.44 \mathrm{~kJ} \mathrm{~mol}^{-1}$, respectively) in comparison to that in absence of inhibitors $\left(11.12 \mathrm{~kJ} \mathrm{~mol}^{-1}\right)$. The positive signs of $\Delta H^{*}$ reflect the endothermic nature of Csteel dissolution activated process which suggests the slow 
Table 8 Activation parameters for carbon steel in oilfield water in absence and presence of 300 ppm GS2, GS6 and GS10

\begin{tabular}{llllll}
\hline Inhibitor & $E_{\mathrm{a}}\left(\mathrm{kJ} \mathrm{mol}^{-1}\right)$ & $r^{2}$ & $\begin{array}{l}\Delta H^{*} \\
\left(\mathrm{~kJ} \mathrm{~mol}^{-1}\right)\end{array}$ & $\begin{array}{l}\Delta S^{*} \\
\left(\mathrm{~J} \mathrm{~mol}^{-1} \mathrm{~K}^{-1}\right)\end{array}$ & $r^{2}$ \\
\hline Blank & 13.59 & 0.8731 & 11.12 & -170.01 & 0.8198 \\
GS2 & 22.37 & 0.9813 & 19.89 & -148.93 & 0.9760 \\
GS6 & 17.70 & 0.9529 & 15.22 & -163.94 & 0.9363 \\
GS10 & 24.92 & 0.9626 & 22.44 & -142.29 & 0.9753
\end{tabular}

dissolution of C-steel surface in presence of inhibitors. ${ }^{38}$ Large and negative values of $\Delta S^{*}$ show that the activated complex in the rate determining step represents an association rather than a dissociation step, meaning that a decrease in disordering or randomness takes place on going from reactants to the activated complex (molecules are in higher ordered state in the activated complex than in the initial state). ${ }^{22}$ Comparing the entropy of activation in both inhibited and uninhibited oilfield water reveals that the values of $\Delta S^{*}$ are less negative in solutions containing GS2, GS6 and GS10 (-148.93, -163.94 and $-142.29 \mathrm{~J}$ $\mathrm{mol}^{-1} \mathrm{~K}^{-1}$, respectively) than for uninhibited solution $(-170.01$ $\mathrm{J} \mathrm{mol}^{-1} \mathrm{~K}^{-1}$ ). The thermodynamic values obtained for $\Delta S^{*}$ are the algebraic sum of the adsorption of inhibitor molecules (solute) and desorption of water molecules (solvent). Hence, the increase in entropy of activation in presence of gemini surfactants is attributed to the increase in the solvent $\left(\mathrm{H}_{2} \mathrm{O}\right)$ entropy as a result of $\mathrm{H}_{2} \mathrm{O}$ molecules desorbed from C-steel surface. ${ }^{38}$

\subsection{Effect of immersion time}

It is of prime importance to study the effect of immersion time on corrosion inhibition to examine the stability of the inhibitor film with time. Weight loss method was employed to evaluate the effect of immersion time on the corrosion rate of C-steel up to four weeks. Fig. 10 shows that oilfield water (free from inhibitor) leads to severe corrosion for C-steel with a corrosion rate being continuously increased during the first two weeks. After that, the corrosion rate drops suddenly till the end of the third week and eventually becomes nearly constant. For C-steel coupons immersed in oilfield water inhibited by any of the three tested gemini surfactants, the corrosion rate continues to

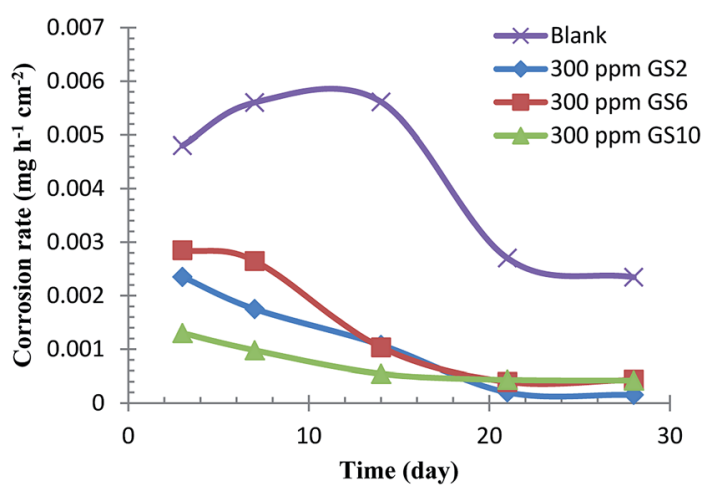

Fig. 10 Effect of immersion time on corrosion rate of carbon steel recorded at room temperature. decrease with time. These results indicate that in blank oilfield water, the continuous increase in corrosion rate during the initial days of immersion could be due to the dissolution of the air-oxide film formed before immersion. In the meantime, the prevailing corrosive species aggressively attack the C-steel and corrosion products (Fe oxides and salts) accumulate on its surface with time forming a somewhat protective film which slightly isolates the C-steel surface from the medium. ${ }^{33}$ After longer immersion time, the amount of corrosion products becomes so much that the aggressive species can hardly attack the metal surface. So, the corrosion process continues but with a decreasing rate. For solutions of oilfield water inhibited by gemini surfactants, the corrosion rate was found to be continuously decreasing with time due to the inhibitive contribution between adsorption film and corrosion products. With prolonging immersion time, more surfactant molecules come in the vicinity of C-steel surface and adsorb on it until the surface is covered with surfactant molecules to its maximum value. After that, surfactant molecules can form multilayers over the surface leading to more enhanced adsorption film and the corrosion process becomes more inhibited. ${ }^{50}$

\subsection{Inhibition mechanism}

It is important to determine the potential of zero charge (pzc) of C-steel in oilfield water to know the charge of steel surface and hence we can explain the adsorption mechanism of gemini surfactants. $^{32}$ Values of pzc for the blank and all inhibited

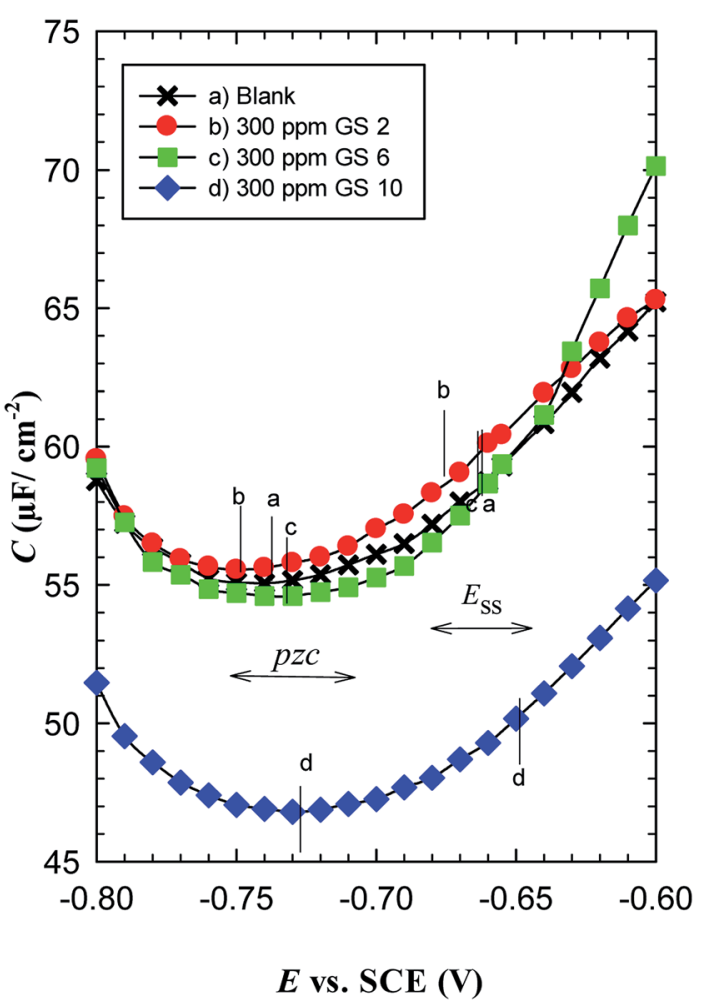

Fig. 11 Variation of the capacitance as a function of potential applied on carbon steel in oilfield water in the absence and presence of gemini surfactants at $293 \mathrm{~K}$. 
Table 9 Comparison between $E_{\mathrm{ss}}$ and pzc

\begin{tabular}{lll}
\hline & $\begin{array}{l}E_{\mathrm{SS}} v s . \\
\text { Inhibitor }\end{array}$ & pze $(\mathrm{mV})$ \\
\hline Blank & & SCE $(\mathrm{mV})$ \\
GS2 & -656 & -737 \\
GS6 & -670 & -760 \\
GS10 & -656 & -738 \\
& -645 & -739
\end{tabular}

(a)

(b)

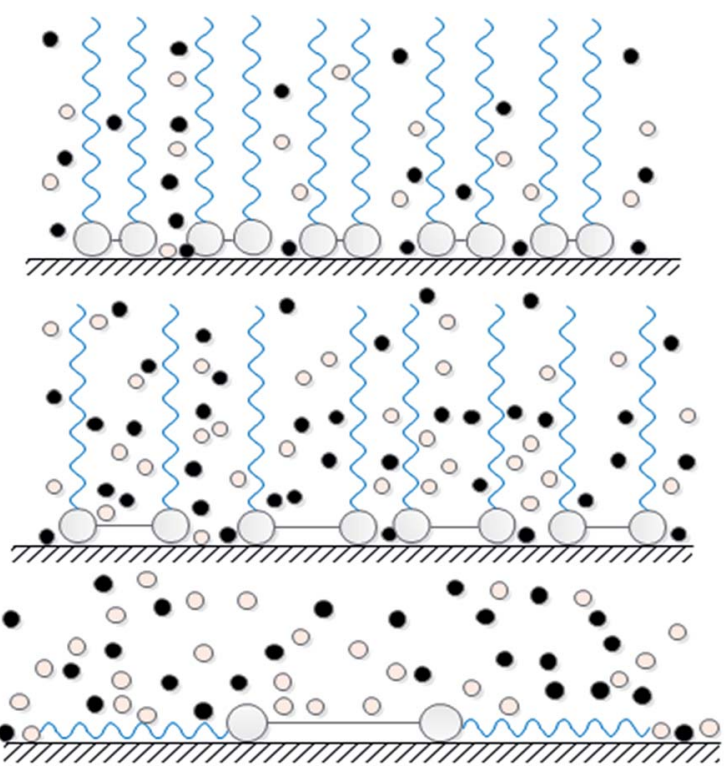

Fig. 12 Adsorption modes of GS2, GS6 and GS10.

oilfield water solutions were calculated from Fig. 11. Table 9 reveals that all pzc values are more negative than their corresponding steady state $\left(E_{\mathrm{ss}}\right)$ values. This means that the C-steel surface either in the blank or inhibited solutions is positively charged at the open-circuit conditions. This observation can be explained such that steels or iron corrode when Fe atoms decompose from their surfaces into positive ions and electrons; $\mathrm{Fe}=\mathrm{Fe}^{2+}+2 \mathrm{e}$ leaving the surface positively charged. In naturally aerated neutral solutions, the released electrons are
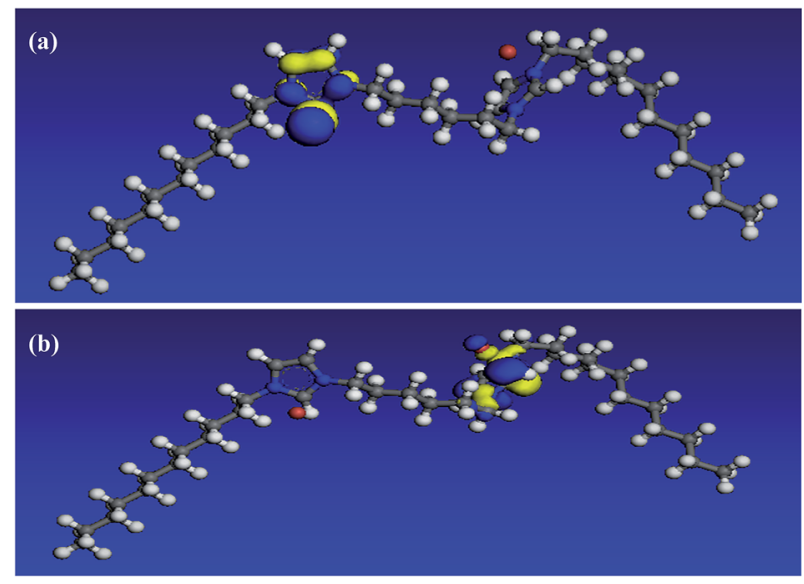

Fig. 14 HOMO (a) and LUMO (b) distributions in GS6 molecule.

involved in oxygen reduction; $\mathrm{H}_{2} \mathrm{O}+\frac{1}{2} \mathrm{O}_{2}+2 \mathrm{e}=2 \mathrm{OH}^{-} .{ }^{22}$ Table 2 shows that the corrosive medium under study is slightly acidic $\left(\mathrm{pH}=6.85\right.$ at $\left.25{ }^{\circ} \mathrm{C}\right)$ so the possible cathodic reactions are oxygen reduction and hydrogen evolution; $2 \mathrm{H}^{+}+2 \mathrm{e}=\mathrm{H}_{2} \cdot{ }^{35}$

Since the C-steel is positively charged either in inhibited or uninhibited oilfield water, the inhibitor molecules can be adsorbed on the metal/solution interface by one or more of the following ways ${ }^{3 \mathbf{8}}$ : (i) donor-acceptor interactions between the $\pi$-electrons of aromatic imidazolium ring and vacant d-orbitals of iron surface atoms. (ii) Unshared electron pairs of tertiary imidazolium $\mathrm{N}$ atoms and vacant d-orbitals of iron surface atoms. (iii) Interaction of d-electrons of iron surface atoms and the positive charge delocalized over the imidazolium ring. Gemini surfactants may also adsorb on positively charged Csteel surface in a manner that anions (e.g. $\mathrm{Cl}^{-}, \mathrm{Br}^{-}$and $\mathrm{HCO}_{3}{ }^{-}$) adsorb directly on C-steel surface then molecules of cationic gemini surfactants adsorb on the anionic layer. ${ }^{35}$

According to Heakal and Elkholy, ${ }^{15}$ research works that have studied the effect of spacer revealed two contradictory opinions: (i) the inhibition efficiency decreases with increasing the length of spacer chain. This behavior has been explained such that the increase in the number of methylene units in the spacer chain leads to an increase in the molecule flexibility. This hinders the
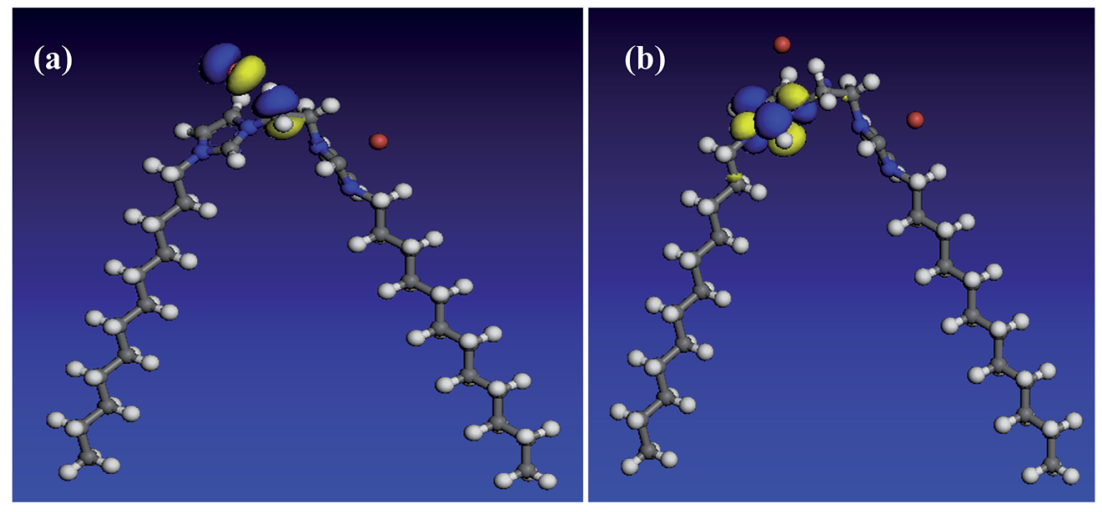

Fig. $13 \mathrm{HOMO}$ (a) and LUMO (b) distributions in GS2 molecule. 

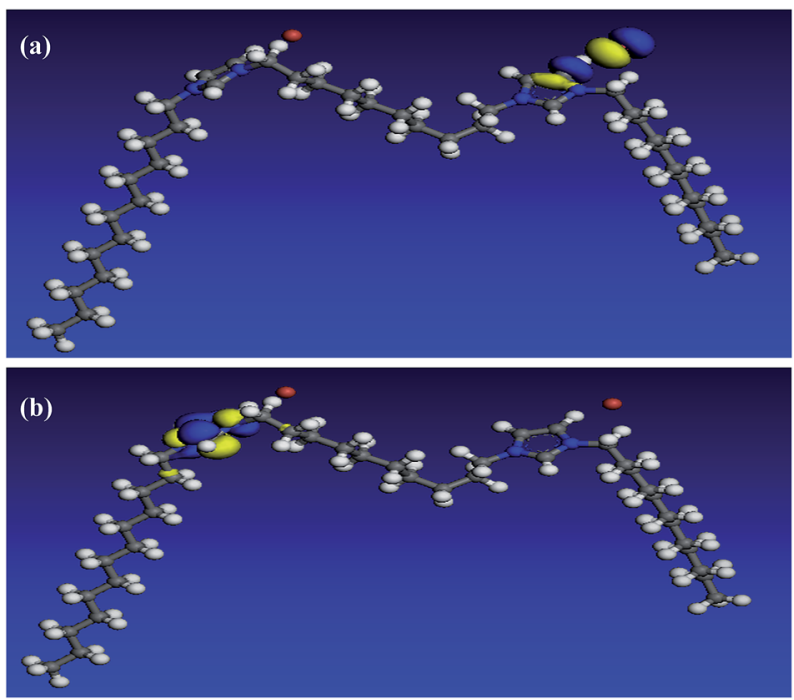

Fig. 15 HOMO (a) and LUMO (b) distributions in GS10 molecule.

adsorption of the gemini surfactant on metal surface and thus the inhibition efficiency decreases. (ii) The inhibition efficiency increases as the length of spacer chain is increased. This can be explained assuming that lengthening the spacer chain increases the degree of surface coverage and also the average area occupied by each adsorbed molecule. Hence, the inhibition efficiency increases. Both phenomena have been observed in our study for the three gemini surfactants having the same terminal chain length (dodecyl group) and differing in the spacer length (2, 6 and 10 methylene groups). Data obtained from electrochemical and chemical measurements confirm that GS10 $>$ GS2 $>$ GS6 in inhibition efficiency as well as their critical concentrations follows the trend: GS10 < GS2 < GS6, i.e. $150 \mathrm{ppm}, 200 \mathrm{ppm}$ and $300 \mathrm{ppm}$, respectively. In other words, GS10 demonstrates higher efficiency at lower concentration than GS2 which, in turn, shows also higher efficiency at lower concentration than GS6. This behavior can be elucidated as follows (Fig. 12):

(1) For the gemini surfactant of shortest spacer (GS2), the very short spacer allows the terminal chains to be very close to each other. So, there is a degree of attraction forces between adjacent chains in the same molecule and between neighboring molecules by hydrophobic interaction. ${ }^{51}$ This leads to the presence of arrays of stacked molecules which represent a barrier against corrosive molecules to penetrate to C-steel surface (Fig. 12(a)).

(2) On the other hand, GS6 has a longer spacer and its terminal chains are far away from each other so there are weak

Table 10 Quantum chemical parameters calculated for GS2, GS6 and GS10

\begin{tabular}{llllllrrr}
\hline Molecule & $E_{\text {номо }}(\mathrm{eV})$ & $E_{\text {LUмо }}(\mathrm{eV})$ & $\Delta E$ & $I(\mathrm{eV})$ & $A(\mathrm{eV})$ & $\chi(\mathrm{eV})$ & $\eta(\mathrm{eV})$ & $\mu(\mathrm{Debye})$ \\
\hline GS2 & -8.357 & -1.071 & 7.286 & 8.357 & 1.071 & 4.714 & 3.643 \\
GS6 & -8.134 & -0.721 & 7.413 & 8.134 & 0.721 & 4.428 & 3.707 & 14.596 \\
GS10 & -8.234 & -1.453 & 6.781 & 8.234 & 1.453 & 4.844 & 3.391 \\
& & & & & & & & \\
\hline
\end{tabular}

(a)
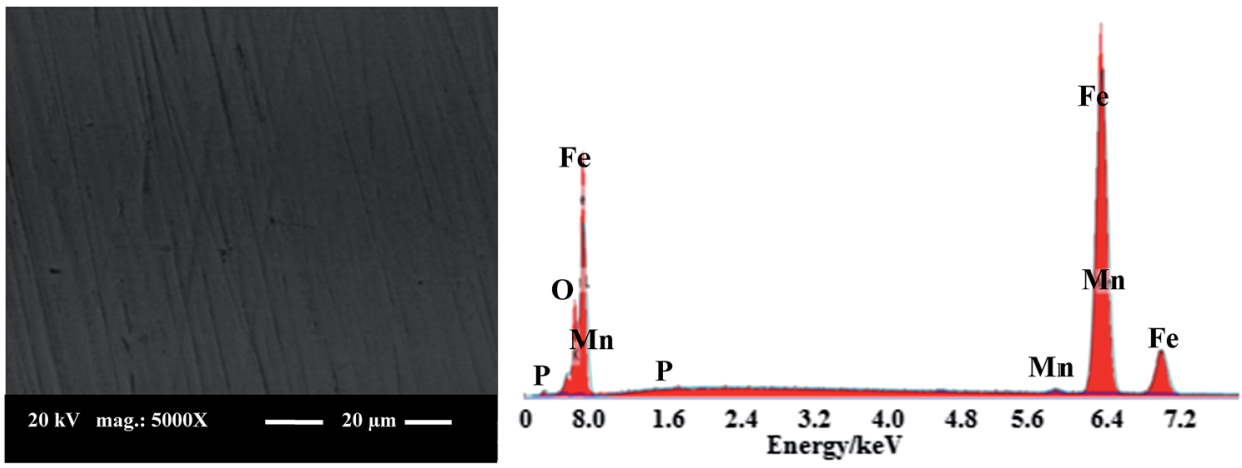

(b)
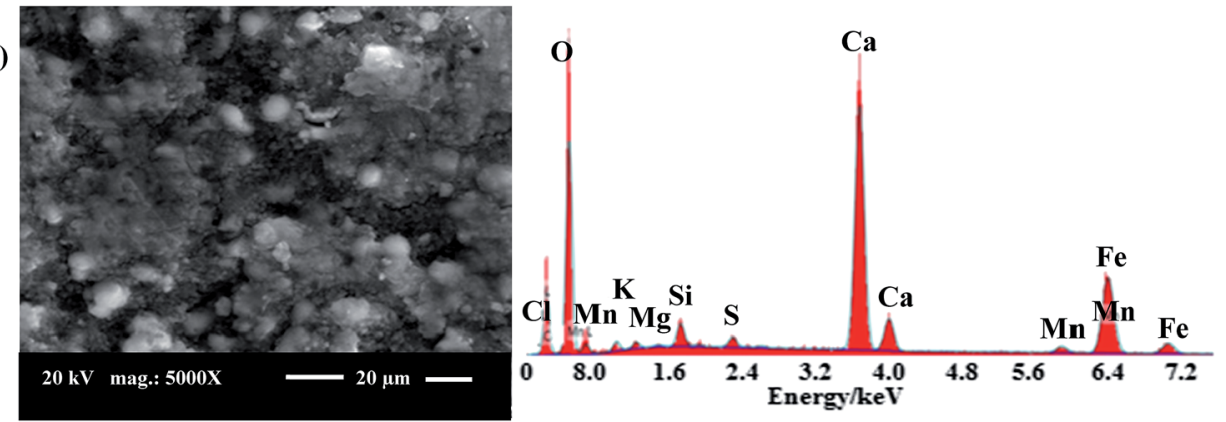

Fig. 16 SEM micrographs and EDX images for: (a) abraded C-steel surface, (b) surface of C-steel immersed in a solution of oilfield water. 
hydrophobic interactions between the terminal chains. In addition, a specific region on C-steel surface can be covered by a number of GS6 less than GS2. In this case there may be voids or weak regions through which corrosive species can attack Csteel surface (Fig. 12(b)).

Unlike GS2 and GS6 whom molecules are predicted to adsorb on C-steel via vertical orientation, GS10 molecules are expected to adsorb on C-steel surface via lateral interactions due to the absence of hydrophobic interactions between terminal chains. So, both terminal chains in GS10 molecule can extend over C-steel surface instead of being extended in the solution (Fig. 12(c)). Moreover, this mode of interaction allows more GS10 molecules to overlay on each other forming multilayers. So, GS10 forms a tough barrier against corrosive species.

A conclusion can be gained from these observations that very short and very long spacer-gemini surfactants are more efficient than those of intermediate spacers. This assumption compromises between the previously mentioned contradictory phenomena concerning the effect of spacer length on the corrosion inhibition efficiency.

\subsection{Quantum chemical calculations}

In an attempt to undergo a correlation between computational chemical calculations and experimental measurements, the quantum chemical parameters are calculated and discussed. All optimization calculations were done using VAMP module in Materials Studio 6.0 software from Accelrys Inc. The Parametric Method (PM3), a semi-empirical method was employed to obtain quantum chemical parameters and to optimize the molecule geometry. ${ }^{52}$ As it can be seen in Fig. 13-15, both HOMO and LUMO regions are focused on imidazolium rings where in each molecule; HOMO is localized on one imidazolium ring while LUMO is distributed over the other ring. This indicates that the imidazolium rings are the active parts in these gemini surfactants. Low values of the gap energy $(\Delta E=$ $\left.E_{\text {LUMO }}-E_{\text {HOMO }}\right)^{20}$ refer to good inhibition efficiencies because the energy needed to remove an electron from the HOMO of an inhibitor will be minimized and also it will be easy to donate electrons for Fe d-orbital. Moreover, $E_{\text {Lumo }}$ will be minimum and thus the inhibitor can gain electrons from filled $\mathrm{Fe} d-$ (a)

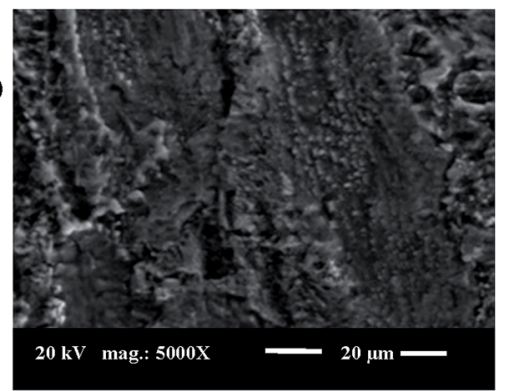

(b)

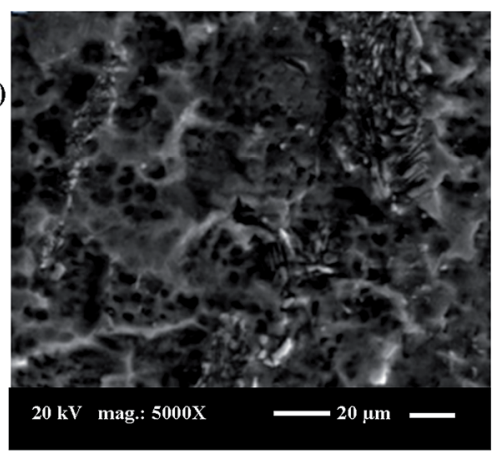

(c)

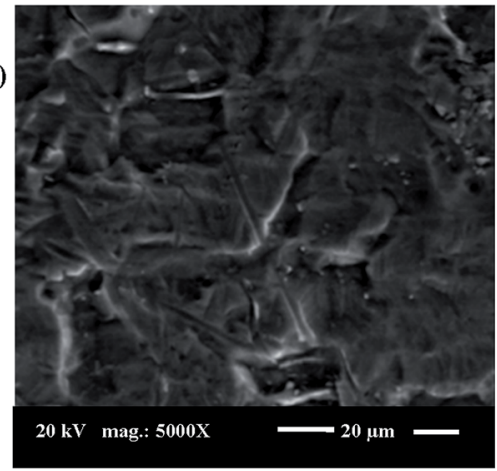

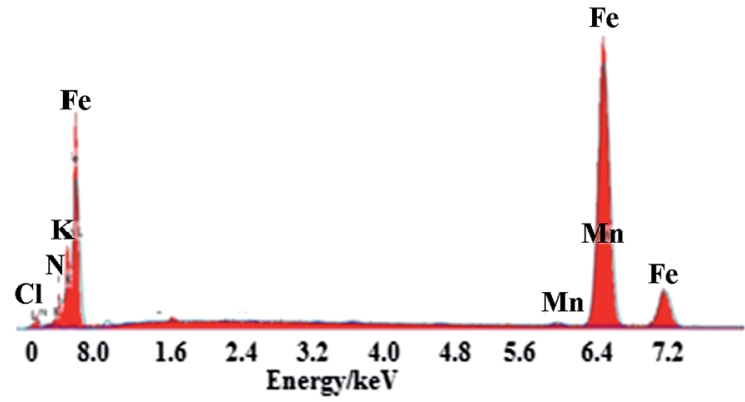
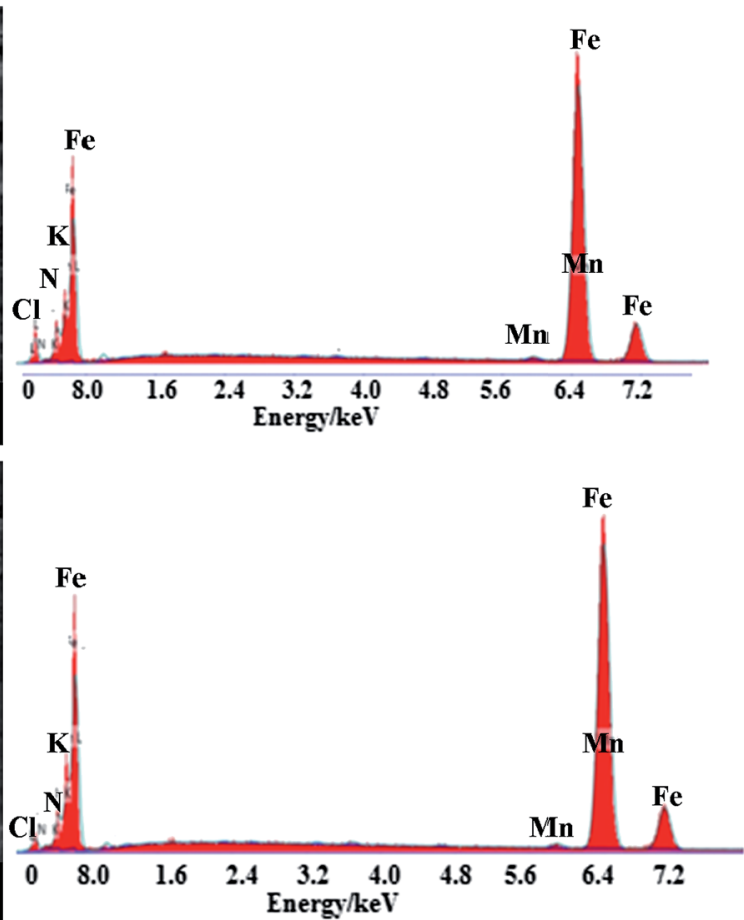

Fig. 17 SEM micrographs and EDX images for surface of C-steel immersed in a solution of oilfield water inhibited by: (a) 300 ppm GS2, (b) 300 ppm GS6 and (c) 300 ppm GS10. 
Table 11 FT-IR stretching absorption bands for gemini surfactants before and after adsorption

\begin{tabular}{|c|c|c|c|c|c|c|c|c|}
\hline Assignment ${ }^{59,60}$ & & & $\mathrm{~N}-\mathrm{H}$ & $\begin{array}{l}\text { Aromatic } \\
\text { C-H }\end{array}$ & $\begin{array}{l}\text { Aliphatic } \\
\text { C-H }\end{array}$ & $\begin{array}{l}\text { Combination } \\
\mathrm{N}-\mathrm{H}\end{array}$ & $\begin{array}{l}\text { Aromatic } \\
\mathrm{C}=\mathrm{C} \text { or } \mathrm{C}=\mathrm{N}\end{array}$ & $\begin{array}{l}\mathrm{C}-\mathrm{Br} \\
\text { or } \gamma-\mathrm{Fe}_{2} \mathrm{O}_{3}\end{array}$ \\
\hline \multirow[t]{4}{*}{ Absorption bands $\left(\mathrm{cm}^{-1}\right)$} & GS2 & Before & 3417 & 3039 & $2922-2852$ & 2042 & 1563 & 636 \\
\hline & \multirow[t]{2}{*}{ GS6 } & Before & 3416 & 3073 & $2924-2854$ & 2062 & 1625 & 635 \\
\hline & & After & 3404 & - & $2924-2854$ & - & 1619 & 590 \\
\hline & GS10 & Before & 3419 & 3070 & $2923-2853$ & 2055 & 1623 & 635 \\
\hline
\end{tabular}

orbital $^{53}$ or from the filled Fe 4 s orbital. ${ }^{54}$ Table 10 reveals that GS10 $<$ GS2 $<$ GS6 in $\Delta E$ giving a theoretical prediction that GS10 $>$ GS2 $>$ GS6 in agreement with the practical results. In literature, there is no regular correlation between the inhibition efficiency of a corrosion inhibitor and its dipole moment $(\mu) .^{20}$

If $\mathrm{Fe}$ and an inhibitor molecule are brought together, electrons will flow from the less electronegative entity to the more electronegative one until the values of the chemical potential become equal. The parameters, electronegativity $(\chi)$ and global hardness $(\eta)$, were calculated for the prepared gemini surfactants. These parameters are related to the electron affinity $(A)$ and ionization potential ( $I$, where: $\chi=\frac{I+A}{2}$ and $\eta=\frac{I-A}{2}$. $I$ and $A$ are related, in turn, to $E_{\text {HOMO }}$ and $E_{\mathrm{LUMO}}$ as: $I=-E_{\mathrm{HOMO}}$ and $A=-E_{\text {Lumo }}{ }^{55}$ Table 10 indicates that GS10 $<$ GS2 $<$ GS6 in the $E_{\mathrm{LUMO}}$ whereas the trend is reversed in the case of the electronegativity of these compounds $(\chi)$. Thus, the more electronegative the molecule, the better its interaction with $\mathrm{Fe}$ surface. These observations indicate that these compounds may act as potential inhibitors for Fe corrosion via electron transfer from the metal surface to inhibitor where the transferred electrons are hosted in the antibonding molecular orbitals (LUMOs) ${ }^{56}$ and the measured inhibition efficiency follows the order GS10 > GS2 > GS6.

\subsection{Surface analysis}

3.7.1. SEM and EDX. SEM analysis is performed for C-steel coupons immersed in blank and inhibited solutions of oilfield water and their SEM micrographs were recorded with a magnification power $(5000 \times)$ in order to observe the changes occurred during corrosion process in the absence and presence of gemini surfactants. Fig. 16(a) shows the SEM micrograph of abraded Csteel surface where the slight scratches occurring by emery papers are clearly visible on the surface. The corresponding EDX spectrum shows that the elements constituting carbon steel sample (Fe, Mn, C and P) appears on EDX spectrum of the abraded sample in addition to the appearance of oxygen related to the air-formed oxide film. Fig. 16(b) shows that C-steel coupon immersed in blank solution was highly damaged and its surface is full of roughness and cavities. These features indicate that C-steel surface was highly corroded in absence of inhibitors. The corresponding EDX spectrum displays the peaks of (Fe, $\mathrm{Ca}, \mathrm{Mg}, \mathrm{Cl}, \mathrm{S}$ and $\mathrm{O}$ ) special for the constituents of oilfield water (e.g. $\mathrm{Ca}^{2+}, \mathrm{Mg}^{2+}, \mathrm{Cl}^{-}$and $\left.\mathrm{SO}_{4}{ }^{2-}\right)$ (Table 2) and iron oxides indicating the accumulation of corrosion products (salts and oxides) on C-steel surface. These features indicate that C-steel surface was highly corroded in oilfield water free from inhibitors. In contrast, Fig. 17 displays that there are fewer damages on C-steel surface in oilfield water inhibited by gemini surfactants following the order: GS10 > GS2 > GS6 in surface protection. Surface enhancement confirms the inhibitive and protective action of these gemini surfactants for C-steel in oilfield water. ${ }^{31}$ The corresponding EDX spectra show that there is a reduction in the amount of corrosion products where the peaks corresponding to salts and oxides formed due to corrosion process are diminished. The reduction in the amount of corrosion products confirms the anti-corrosion effect of these gemini surfactants for C-steel in oilfield water.

3.7.2. FT-IR. FT-IR is a powerful technique that is always used for determining the type of bonding of organic inhibitors adsorbed on the metal surface. ${ }^{57}$ Compared to those of pure gemini surfactants, FT-IR absorption bands for the corrosion products scratched from C-steel surface immersed in oilfield water containing gemini surfactants are shifted from their positions and some bands disappeared (Table 11). These results strongly support the presence of interaction between the molecules of these gemini surfactants and the metal surface confirming the occurrence of adsorption process. ${ }^{58}$

\section{Conclusions}

This study evaluates three novel gemini surfactants as inhibitors for the corrosion of C-steel in oilfield water. The main conclusions are as follows:

(1) Weight loss method, polarization and EIS measurements have showed that the synthesized gemini surfactants (GS2, GS6 and GS10) are good inhibitors for the corrosion of C-steel in oilfield water and the inhibition efficiency increases with the inhibitor concentration up to a critical value above which the inhibition efficiency starts to decrease.

(2) The maximum inhibition efficiency values obtained from weight loss method for GS2, GS6 and GS10 are $67.64 \%$ at $200 \mathrm{ppm}, 62.30 \%$ at $300 \mathrm{ppm}$ and $85.21 \%$ at $150 \mathrm{ppm}$, respectively.

(3) EIS spectra of C-steel in oilfield water in absence and presence of any of the tested inhibitors show a two-time constant behavior and displays the features of Warburg impedance. 
(4) The synthesized gemini compounds act as mixed-type corrosion inhibitors, retarding both anodic metal dissolution and cathodic reactions.

(5) The decrease in corrosion rate of C-steel as a function of each inhibitor concentration (till its critical value) indicates that its molecules adsorb on C-steel surface.

(6) Adsorption of molecules of each gemini surfactant is described according to Langmuir isotherm. Both physisorption and chemisorption processes are present but the former is predominant.

(7) Thermodynamic parameters calculated from polarization measurements indicate that the presence of these inhibitors increases the activation energy and these compounds are spontaneously adsorbed on C-steel surface mainly via physisorption mechanism.

(8) Surface analyses (SEM, EDX and FT-IR) confirm the adsorption of these inhibitors on C-steel surface.

\section{Conflicts of interest}

There are no conflicts to declare.

\section{References}

1 M. Deyab and S. Keera, Egypt. J. Pet., 2012, 21, 31-36.

2 M. A. Migahed, M. M. Attya, S. M. Rashwan, M. Abd El-Raouf and A. M. Al-Sabagh, Egypt. J. Pet., 2013, 22, 149-160.

3 M. A. Deyab, Desalination, 2016, 384, 60-67.

4 P. Boschee, Soc. Petrol. Eng. J., 2012, 1, 22-26.

5 M. A. M. Deyab, J. Surfactants Deterg., 2015, 18, 405-411.

6 D. Lopez, S. Simison and S. De Sanchez, Corros. Sci., 2005, 47, 735-755.

7 M. Bobina, A. Kellenberger, J.-P. Millet, C. Muntean and N. Vaszilcsin, Corros. Sci., 2013, 69, 389-395.

8 M. Deyab, RSC Adv., 2015, 5, 41365-41371.

9 M. Deyab, J. Taiwan Inst. Chem. Eng., 2016, 60, 369-375.

10 M. Prabakaran, S.-H. Kim, V. Hemapriya, M. Gopiraman, I. S. Kim and I.-M. Chung, RSC Adv., 2016, 6, 57144-57153.

11 M. V. Fiori-Bimbi, P. E. Alvarez, H. Vaca and C. A. Gervasi, Corros. Sci., 2015, 92, 192-199.

12 L. Fragoza-Mar, O. Olivares-Xometl, M. A. DomínguezAguilar, E. A. Flores, P. Arellanes-Lozada and F. JiménezCruz, Corros. Sci., 2012, 61, 171-184.

13 P. Brown, T. Alan Hatton and J. Eastoe, Curr. Opin. Colloid Interface Sci., 2015, 20, 140-150.

14 M. A. Amin, M. A. Ahmed, H. A. Arida, F. Kandemirli, M. Saracoglu, T. Arslan and M. A. Basaran, Corros. Sci., 2011, 53, 1895-1909.

15 F. El-Taib Heakal and A. E. Elkholy, J. Mol. Liq., 2017, 230, 395-407.

16 R. Zana and J. Xia, Gemini surfactants: synthesis, interfacial and solution-phase behavior, and applications, Marcel Dekker, New York, 2003.

17 F. El-Taib Heakal, M. M. Osman, M. A. Deyab and A. E. Elkholy, Z. Phys. Chem., 2017, 231, DOI: 10.1515/zpch2017-0949.
18 M. Deyab, M. Osman, A. Elkholy and F. El-Taib Heakal, RSC Adv., 2017, 7, 45241-45251.

19 M. Deyab, K. Eddahaoui, R. Essehli, T. Rhadfi, S. Benmokhtar and G. Mele, Desalination, 2016, 383, 38-45.

20 H. M. Abd El-Lateef, M. A. Abo-Riya and A. H. Tantawy, Corros. Sci., 2016, 108, 94-110.

21 J. M. Zhao, H. B. Duan and R. J. Jiang, Corros. Sci., 2015, 91, 108-119.

22 F. El-Taib Heakal, A. S. Fouda and M. S. Radwan, Mater. Chem. Phys., 2011, 125, 26-36.

23 M. A. Amin, S. S. A. El-Rehim, E. El-Sherbini and R. S. Bayoumi, Electrochim. Acta, 2007, 52, 3588-3600.

24 M. A. Deyab and S. S. A. El-Rehim, J. Taiwan Inst. Chem. Eng., 2014, 45, 1065-1072.

25 F. Ivušić, O. Lahodny-Šarc, H. O. Ćurković and V. Alar, Corros. Sci., 2015, 98, 88-97.

26 Q. Deng, H.-W. Shi, N.-N. Ding, B.-Q. Chen, X.-P. He, G. Liu, Y. Tang, Y.-T. Long and G.-R. Chen, Corros. Sci., 2012, 57, 220-227.

27 F. El-Taib Heakal and S. Haruyama, Corros. Sci., 1980, 20, 887-898.

28 A. El Bribri, M. Tabyaoui, B. Tabyaoui, H. El Attari and F. Bentiss, Mater. Chem. Phys., 2013, 141, 240-247.

29 A. M. Awad, O. S. Shehata and F. El-Taib Heakal, Appl. Surf. Sci., 2015, 359, 939-947.

30 A. E. Elkholy, M.Sc. thesis, Cairo University, 2017.

31 A. Singh, Y. Lin, E. E. Ebenso, W. Liu, J. Pan and B. Huang, J. Ind. Eng. Chem., 2015, 24, 219-228.

32 H. Bentrah, Y. Rahali and A. Chala, Corros. Sci., 2014, 82, 426-431.

33 Q. Qu, Y. He, L. Wang, H. Xu, L. Li, Y. Chen and Z. Ding, Corros. Sci., 2015, 91, 321-329.

34 S. Banerjee, V. Srivastava and M. Singh, Corros. Sci., 2012, 59, 35-41.

35 M. Lebrini, F. Robert, H. Vezin and C. Roos, Corros. Sci., 2010, 52, 3367-3376.

36 G. Mu, T. Zhao, M. Liu and T. Gu, Corrosion, 1996, 52, 853856.

37 X. Jiang, Y. Zheng and W. Ke, Corros. Sci., 2005, 47, 26362658.

38 D. K. Yadav, M. Quraishi and B. Maiti, Corros. Sci., 2012, 55, 254-266.

39 G. Karthik and M. Sundaravadivelu, Egypt. J. Pet., 2016, 25, 183-191.

40 A. Satapathy, G. Gunasekaran, S. Sahoo, K. Amit and P. Rodrigues, Corros. Sci., 2009, 51, 2848-2856.

41 S. K. Shukla and M. Quraishi, J. Appl. Electrochem., 2009, 39, 1517-1523.

42 S. M. Tawfik and M. F. Zaky, Res. Chem. Intermed., 2015, 41, 8747-8772.

43 A. M. Al-Sabagh, N. G. Kandile, N. M. Nasser, M. R. Mishrif and A. E. El-Tabey, Egypt. J. Pet., 2013, 22, 351-365.

44 M. Deyab, R. Essehli and B. El Bali, RSC Adv., 2015, 5, 4886848874.

45 M. A. Migahed, M. M. Shaban, A. A. Fadda, T. A. Ali and N. A. Negm, RSC Adv., 2015, 5, 104480-104492. 
46 N. A. Odewunmi, S. A. Umoren, Z. M. Gasem, S. A. Ganiyu and Q. Muhammad, J. Taiwan Inst. Chem. Eng., 2015, 51, 177-185.

47 J. C. da Rocha, J. A. d. C. P. Gomes and E. D'Elia, Corros. Sci., 2010, 52, 2341-2348.

48 M. Hegazy, M. Abdallah and H. Ahmed, Corros. Sci., 2010, 52, 2897-2904.

49 D. Dwivedi, K. Lepková and T. Becker, RSC Adv., 2017, 7, 4580-4610.

50 D. Asefi, M. Arami and N. M. Mahmoodi, Corros. Sci., 2010, 52, 794-800.

51 W. Ansari, J. Aslam and U. Siddiqui, J. Mol. Liq., 2012, 174, 510.

52 A. Y. Musa, A. A. H. Kadhum, A. B. Mohamad and M. S. Takriff, Mater. Chem. Phys., 2011, 129, 660-665.
53 E. Oguzie, C. Enenebeaku, C. Akalezi, S. Okoro, A. Ayuk and E. Ejike, J. Colloid Interface Sci., 2010, 349, 283-292.

54 F. El-Taib Heakal, A. Fouda and S. Zahran, Int. J. Electrochem. Sci., 2015, 10, 1595-1615.

55 F. El-Taib Heakal, S. A. Rizk and A. E. Elkholy, J. Mol. Struct., 2017, DOI: 10.1016/j.molstruc.2017.09.079.

56 F. El-Taib Heakal, S. K. Attia, S. A. Rizk, M. A. Abou Essa and A. E. Elkholy, J. Mol. Struct., 2017, 1147, 714-724.

57 X. Li, S. Deng, H. Fu and T. Li, Electrochim. Acta, 2009, 54, 4089-4098.

58 T. Ramde, S. Rossi and C. Zanella, Appl. Surf. Sci., 2014, 307, 209-216.

59 B. Stuart, Infrared spectroscopy, Wiley Online Library, 2005.

60 L. Chauhan and G. Gunasekaran, Corros. Sci., 2007, 49, 1143-1161. 